\title{
1 Genomic imprinting drives eusociality
}

2 Kenji Matsuura ${ }^{1, \# \star}$, Hiromu Ito ${ }^{2, \#}$, Kazuya Kobayashi ${ }^{3}$, Haruka Osaki $^{4}$, Jin Yoshimura ${ }^{2}$,

3 Edward L. Vargo 5

$4{ }^{1}$ Laboratory of Insect Ecology, Graduate School of Agriculture, Kyoto University, Kyoto,

5 Japan. ${ }^{2}$ Department of International Health and Medical Anthropology, Institute of

6 Tropical Medicine, Nagasaki University. Nagasaki, Japan. ${ }^{3}$ Hokkaido Forest Research

7 Station, Field Science Education and Research Center, Kyoto University, Shibecha,

8 Hokkaido, Japan. ${ }^{4}$ Department of Biology, Kyushu University, Fukuoka, Japan.

$9{ }^{5}$ Department of Entomology, Texas A\&M University, College Station, TX, USA. "These

10 authors contributed equally.

11 *Kenji Matsuura

12 Email: matsuura.kenji.6s@kyoto-u.ac.jp

13 Author Contributions: K.M. initiated and directed the research. K.M. and H.I developed

14 the model with contributions from K.K., H.O, J.Y. and E.V. H.I. carried out the numerical

15 simulations and mathematical analysis. K.M. and H.O. draw illustrations. H.I., K.K. and

16 K.M. generated figures of numerical simulations. All authors interpret the results of

17 simulations. K.M., H.I., J.Y. and E.V. wrote the manuscript.

18 Competing Interest Statement: The authors declare no competing interests.

19 Keywords: origin of eusociality, termite, epigenetic inheritance, sex antagonism 


\section{Abstract}

25 The origin of eusociality, altruistically foregoing personal reproduction to help others, has

26 been a long-standing paradox ever since Darwin. Most eusocial insects and rodents

27 likely evolved from subsocial precursors, in which older offspring "helpers" contribute to

28 the development of younger siblings without a permanent sterile caste. The driving mechanism for the transition from subsociality (with helpers) to eusociality (with lifelong

30 sterile workers) remains an enigma because individuals in subsocial groups are subject

31 to direct natural selection rather than kin selection. Our genomic imprinting theory

32 demonstrates that natural selection generates eusociality in subsocial groups when

33 parental reproductive capacity is linked to a delay in the sexual development of offspring

34 due to sex-antagonistic action of transgenerational epigenetic marks. Focusing on

35 termites, our theory provides the missing evolutionary link to explain the evolution of

36 eusociality from their subsocial wood-feeding cockroach ancestors, and provides a novel

37 framework for understanding the origin of eusociality.

\section{Introduction}

40 The origin of eusociality poses a major challenge to Darwin's theory of natural selection

41 (Darwin, 1859) and it remains a subject of debate today (Kay et al., 2020; Nowak et al.,

42 2010; Wilson and Hölldobler, 2005). Eusociality is an advanced state of sociality

43 characterized by the presence of workers that forego personal reproduction in exchange

44 for altruistic behavior toward close relatives. It has long been studied within the paradigm

45 of inclusive fitness and kin selection (Hamilton, 1964). However, the role of kin selection

46 in the origin of eusociality remains controversial (Wilson and Hölldobler, 2005).

47 Explanations of the origin of new traits are faced with the "selection paradox," the notion

48 that selection cannot act on traits that do not yet exist, and therefore cannot directly

49 cause novelty (Jacob, 1977; Müller and Wagner, 1991). While biologists have made

50 great progress in the last 150 years in understanding how existing traits diversify, we

51 have made less progress in understanding how novel traits arise in the first place. What

52 generates the novelty-here the first appearance of sterile workers?

53 In colonies of eusocial insect (ants, bees, wasps and termites), workers take on non-

54 reproductive tasks and contribute to their parents' reproduction (Wilson, 1971). The

55 colony essentially behaves as a superorganism operating as a functionally integrated 
unit, analogous to the organization of unitary organisms (Hölldobler and Wilson, 2009).

57 In eusocial colonies, the worker caste is an extended phenotype of the parents. Unlike

58 unitary organisms, however, the extended phenotype of a social insect colony enables

59 selection to act at both the individual (within-colony selection) and colony levels

60 (between colony selection). Suppose the first eusocial colony appears on Earth. This

61 colony uniquely has lifelong sterile workers, while all other attributes are identical to

62 other colonies. Initially, the colony cannot compensate for the loss of fitness due to

63 sterility of some offspring unless the parents can simultaneously increase their

64 reproductive output to produce a greater number of fertile offspring. One or more

65 underlying mechanisms are required to link worker sterility with increased reproductive

66 capacity of the parents.

67 Termite societies, like those of eusocial Hymenoptera (ants and some bees and

68 wasps), are generally large families with a reproductive division of labor. These two

69 groups evolved complex societies independently with different life history pre-

70 adaptations for social evolution. Termites are the oldest social insects, with societies

71 dating back to 150 million years ago (Bourguignon et al., 2015). Eusociality in termites

72 evolved from a subsocial precursor that lived in close family groups and occupied dead

73 trees, as in its sister group Cryptocercidae (woodroaches) (Thorne, 1997) (Fig. 1). The

74 confined nest cavities, slow development due to poor nutritional quality of wood, and

75 need for refaunation of obligate gut symbionts selected for parental care and long-term

76 associations of monogamous family groups (Nalepa, 1994). One requisite condition for

77 the origin of eusociality is iteroparity, which is not present in extant semelparous

78 woodroaches (Korb, 2008; Thorne, 1997). In the subsocial ancestor, iteroparous parents

79 produced brood of staggered age classes living together, where all surviving offspring

80 eventually matured into reproductive imagoes and dispersed to found new colonies.

81 The evolutionary transition from subsociality to eusociality, where the older brood

82 spend a prolonged period in the immature stages within the natal nest and eventually

83 become lifelong workers that contribute to the production of younger brood, is an enigma

84 (Korb, 2008; Thorne, 1997). Although the shift of brood care from parents to older

85 offspring, i.e., helpers, allows the parents to engage more in reproduction, selection is

86 still acting at the individual level rather than the colony level at the subsocial stage. Why

87 did helpers delay and eventually sacrifice their own reproduction under individual-level

88 selection? We show that this paradox can be solved by genomic imprinting. 
89 Recent studies reveal that the transfer of epigenetic marks from parents to offspring 90 can influence offspring phenotype independently of DNA sequence (Bonduriansky and

91 Day, 2008; Chong and Whitelaw, 2004; Ferguson-Smith, 2011; Jablonka and Raz,

92 2009). Such 'epigenetic inheritance' provides the key to many unsolved puzzles in a

93 wide range of biological processes by circumventing the limitations of genetic inheritance

94 (Bonduriansky and Day, 2008; Matsuura, 2020a; Pál and Miklós, 1999). Genomic

95 imprinting can be differentially marked in eggs and sperm, and inheritance of these

96 epigenetic marks causes genes to be expressed in a parental-origin-specific manner in

97 the offspring (Reik and Walter, 2001). Genomic imprinting has been proposed as a

98 mechanism underlying the parental effects on caste determination (Matsuura et al.,

99 2018) and the evolution of asexual queen succession in termites (Matsuura, 2017;

100 Matsuura et al., 2018, 2009) (see supplementary text, Figs. S1 and S2). Thus, queen-

101 and king-specific epigenetic marks antagonistically influence the development of

102 offspring resulting in "neuter" workers whose sexual development is suppressed due to

103 counterbalanced maternal and paternal imprinting.

104

105

106

107

108

109

110

111

112

113

114

115

116

117

118

119

120

121

\section{Model}

General framework. To consider the evolutionary transition from subsocial to eusocial in the ancestor of termites, we suppose a diploid subsocial organism in which a male and a female cooperatively found a new colony in an enclosed habitat. We performed evolutionary simulations by running colony generation $G$, where each generation includes a colony life cycle as a part of the simulation (Fig. 2, Fig. S6). The colony life cycle is given as follows. An individual has longevity $\Phi$ (years), where its age $i$ varies from 0 to $\Phi$. Individuals spend $\tau$ ( $\geq \tau_{\min }$ : the shortest time to become alates) in their natal nests and become alates that disperse. The colony dies when the parents die. Thus, colony longevity $T$ is given by $\Phi-\tau$ (Fig. 2A), where colony age $t$ varies from 0 to $T$. Fitness gain $\omega_{t}$ of the colony at $t$ is the sum of the reproductive values of dispersing alates (Fig. 2A). Total fitness of the colony $W$ is given by $W=\sum_{t=0}^{T} \omega_{t}$.

Colony foundation. We consider a monogamous pair of a male and a female founding a new colony in a nest inside wood. The work performance of each parent is $\rho(\mathrm{J} / \mathrm{year})$, 
122 that is, the amount of resources acquired by a parent. Both the male and female founder

123 contribute to the production of eggs equally. The available resources for egg production

124 of a $t$-year-old colony is $R_{t}$. In the first year (0-year-old colony), the parents produce

125 eggs by using the available resources $R_{0}(\mathrm{~J})(=2 \rho)$ (Fig. $\left.2 B\right)$. The number of first brood

126 eggs $F_{0}$ is given by

$127 \quad F_{0}=\frac{\alpha R_{0}}{r}=\frac{2 \alpha \rho}{r}$

128 where $\alpha$ is the metabolic efficiency of the parents to convert the resources into eggs, $r$ is

129 the cost for producing one egg. For simplicity, we set $\alpha / r=1$, i.e., $F_{0}=2 \rho$. The final

130 family composition of the 0 -year-old colony is: a founding male, a founding female and

131 first brood ( $F_{0}$ eggs).

132 Second year (1-year-old colony): The 1st brood develop into 1-year old larvae, which

133 are too small and undeveloped to contribute to social labor. In the second year, the

134 available resources $R_{1}(\mathrm{~J})$ are still $2 \rho$. Parents produce $F_{0}$ eggs of the 2 nd brood in the

135 second year. Therefore, the final family composition of the 1-year-old colony is: a

136 founding male, a founding female, first brood ( $F_{0} 1$-year-old larva) and 2 nd brood $\left(F_{0}\right.$

137 eggs).

138 In the third year, the 2nd brood are 1-year-old, which do not contribute to social labor.

139 The 1st brood are 2-years-old, at which time they begin to contribute to social labor as

140 helpers.

141

142 Work performance of helpers. Work performance $P_{i}$ (J/year) of a helper offspring

143 increases with age $i$. Eggs (0-year-old) and 1-year-old larva do not contribute to social

144 labor. Offspring older than 5 years achieve the maximum performance $\beta \cdot \rho$ in their

145 lifetime, where $\beta$ is the relative work efficiency of helpers compared to the work

146 performance of a parent $\rho$ (Figs. S3 and S4). If $\beta$ is 1, mature helpers (offspring older

147 than 5 years) have the same work performance as a parent. The 2-4 year old offspring

148 have intermediate performance. Hence, the work performance $P_{i}$ of a helper at age $i$

149 (year) is given by

$150 \quad P_{i}=\left\{\begin{array}{lr}0 & (i=0) \\ \frac{\beta \rho(i-1)}{4} & (1 \leq i \leq 5) \\ \beta \rho & (i>5)\end{array}\right.$

151 Total acquired resources $R_{t}(\mathrm{~J})$ are 
$R_{t}=2 \rho+\sum H_{i} \cdot P_{i}$

where $H_{i}$ is the number of $i$-year-old helpers.

Reproductive capacity and genomic imprinting. Relationship between the amount of resources $R_{t}$ and the number of eggs $F_{t}$ produced in year $t$ is given by

$157 \quad F_{t}=\left\{\begin{array}{l}\frac{\alpha R_{t}}{r}, \frac{\alpha R_{t}}{r}<C_{t} \\ C_{t}, \frac{\alpha R_{t}}{r} \geq C_{t}\end{array}\right.$,

158 where $C_{t}$ is the reproductive capacity of the parents at colony age $t$ (Fig. $3 A$ ).

159 Reproductive capacity of the parents $C_{t}$ increases with their sexual development.

160 Reproductive capacity of the parents $C_{t}$ is given by

$161 C_{t}=K_{G} \cdot \tanh (t+1)$,

162 where $K_{G}$ is the maximum fecundity of the parents (Fig. $3 A$ ).

163 The maximum reproductive capacity $K_{G}$ is determined by sexual development of the 164 parents, which is acquired through canalization of the expression of sexual development 165 genes through epigenetic modification (epimark level) $E_{t}$ (Fig. 3B).

$166 \quad E_{t}=\frac{d C_{t}}{d t}=\frac{4 K_{G}}{\left\{e^{t+1}+e^{-(t+1)}\right\}^{2}}$.

167 Epigenetic marks are partially inherited by offspring, which leads to a genomic imprinting 168 effect on the sexual development of the offspring. Therefore, imprinting level $I_{t}$ at colony 169 age $t$ is given by

$170 \quad I_{t}=\varepsilon E_{t}$.

171 where $\varepsilon$ is the transmission rate of parental epimarks to offspring (Fig. $3 B$ ).

172 Antagonistic action of paternal imprinting $I_{m}$ and maternal imprinting $I_{f}$ delay the initiation

173 of sexual development of offspring, resulting in prolongation of the offspring's time to 174 become alates $\tau$ (Fig. 3C). For simplicity, we assume

$175 I_{m}=I_{f}=I_{t}$.

177 Genomic imprinting and maturation delay of offspring. The time $\tau$ required to become 178 alates, numerically calculated from $I_{t}$ and its boundary conditions, is given by $\tau_{t}=\left\{\begin{array}{ll}\tau_{\min } & \left(I_{t} \leq \tau_{\min }\right) \\ I_{t} & \left(\tau_{\min }<I_{t}\right)\end{array}\right.$.

180 The offspring that have spent $\tau_{t}$ after hatching in year $t$ become alates, contributing to the 181 founders' fitness (Fig. $2 A$ ). We set $\tau_{\min }=4$ (years) based on the subsocial sister group 
182 Cryptocercus woodroaches, whose maturity takes about 6 years (Cleveland et al., 1934;

183 Nalepa, 1984). Note that when an offspring stays longer in the colony as a helper, its direct 184 contribution to the yearly fitness is not only delayed, but also its residual life span as a 185 colony founder is shortened. However, its contribution as a helper will increase the 186 production of future offspring (younger brothers and sisters) in the current colony (Fig. 2B). 187 This trade-off between the contribution by staying as helpers and leaving success as 188 alates is key for the evolution of eusociality.

Colony fitness and selection process. Fitness gain $\omega_{G, t}$ of the colony at $t$ is the sum of 191 the reproductive values of dispersing alates with different ages $i$, such that $192 \omega_{G, t}=\sum A_{i, t} \cdot q_{G, i}$,

193 where $A_{i, t}$ is the number of alates at age $i$ produced in year $t$ and $q_{G, i}$ is the reproductive 194 value of an alate at age $i$. In exchange for a prolonged helper period, the reproductive 195 value of an alate $q_{G, i}$ declines with the shortening of its residual life span $(\Phi-i)$ after 196 colony foundation. This discounted reproductive value of an alate at age $i$ is numerically 197 calculated from the fitness function $\omega_{G-1, t}$ of the previous generation $G-1$, such that

$198 \quad q_{G, i}=\frac{\sum_{t=0}^{\Phi-i} \omega_{G-1, t}}{\sum_{t=0}^{\Phi-\tau_{\min }} \omega_{G-1, t}}$.

199 In order to calculate the fitness of the first generation $\omega_{1, t}$, we set $q_{1, i}=1$ because there 200 is no imprinting effects on offspring (all offspring reaching age $\tau_{\min }$ become alates without 201 delay). Total fitness of generation $G$ is given by

$202 W_{G}=\sum_{t=0}^{T} \omega_{G, t}$,

203 where $T=\Phi-\tau$.

204 When the resources exceed the maximum reproductive capacity of the parents $K_{G}$, 205 there is no benefit to the colony since they cannot be used to produce additional eggs. 206 The maximum amount of excess resources $\Delta R$ due to the limitation of reproductive 207 capacity $K_{G}$ is given by

$208 \Delta R=R_{G, \max }-\frac{r K_{G}}{\alpha}$,

209 where $R_{G, \max }$ is the maximum yearly resources of a colony at generation $G$. Mutation from $210 K$ to $K+1$ takes place if $\Delta R \geq \frac{r}{\alpha}$ (at least one egg can be produced by the surplus 211 resource) (Fig. 2C, Figs. S5 and S6). Then selection should fix this mutation if $W_{G} \geq W_{G-1}$ 212 (fitness can be increased by mutation). Higher reproductive capacity results from 
213 increased epigenetic modification (i.e., stronger canalization (Rice et al., 2016)) of sexual

214 development genes, which results in a higher imprinting level in offspring. Greater

215 imprinting further prolongs the helper period resulting in in increased resources in the next

216 generation $G+1$, which again produces surplus resources $\Delta R$. This whole process may

217 be repeated to increase reproductive capacity $K_{G}$ as long as the two above-mentioned

218 conditions are satisfied (Figs. S5 and S6). We consider that eusociality arises at the time

219 when the first-brood offspring lose all direct fitness. We also note the time at which the

220 first-brood helpers spend their whole life in the colony, i.e., the appearance of lifelong

221 helpers.

\section{Results}

224 We show that genomic imprinting can explain the origin of eusociality, i.e., the first

225 occurrence of a lifelong neuter caste. To consider the evolutionary transition from

226 subsocial to eusocial in the ancestor of termites, we suppose a diploid subsocial

227 organism in which a male and a female cooperatively found a new colony in an enclosed

228 habitat (Figs. 1F, 1G and 2). We developed a genomic imprinting model that predicts the

229 evolution of eusociality via natural selection when parental reproductive capacity is

230 linked to a delay in the sexual development of offspring through transgenerational

231 epigenetic marks that act in a sex-antagonistic manner. We performed evolutionary

232 simulations by running colony generation, where each generation includes a colony life

233 cycle as a part of the simulation (Fig. 2, Fig. S6). Presence of helpers contribute to social

234 labor, which increases the resources available for egg production (Fig. 2B). Selection

235 favors higher reproductive capacity of the parents so as to fully utilize the available

236 resources (Fig. 2C). Acquisition of greater reproductive potential is derived from higher

237 epigenetic modification (canalization) of the genes for sexual development (Fig. $3 A$ and

238 B). This leads to higher genomic imprinting and thus to the prolonged helper period of

239 the offspring (Fig. 3C).

240 Our numerical algorithm demonstrates that genomic imprinting can drive eusociality via 241 natural selection on colony founders (Fig. 4). The evolutionary transition from subsocial to 242 eusocial systems readily occurs when the epimark transmission rate $\varepsilon$ and/or the helpers' 243 work performance $\beta$ are high (Fig. 4A). Because helpers increase the resources available 244 for egg production (Figs. S3 and S4), natural selection acts on the parents to increase 
245 production of alates. Greater reproductive potential requires higher levels of epigenetic 246 modification. Trans-generational carry-over of sex-specific epimarks leads to higher 247 genomic imprinting and thus to a prolonged helper period for offspring. This evolutionary 248 feedback between natural selection and genomic imprinting facilitates the transition from 249 subsociality to eusociality (Fig. 4B). At some generation, the first-brood offspring lose their 250 direct fitness (the origin of eusociality, red arrowheads in Fig. $4 B$ and $C$ ), and then spend 251 their entire life in the colony as helpers (open arrowheads in Fig. $4 B$ and $C$ ). Here the 252 offspring are essentially the extended phenotype of the parents via genomic imprinting.

253 This feedback process generating eusociality creates parent-offspring conflict

254 frequently because the first brood decreases its direct (and even inclusive) fitness by

255 prolonged helper periods (zigzag black and red lines in Fig 4B), but eventually increases

256 its inclusive fitness. Eusociality can still be achieved even if the helpers' work

257 performance is reduced by one-half $(\beta=0.8 \rightarrow 0.4)$, although increase in the rate of

258 parental direct fitness is slowed down (Fig. 4C). When the helpers' work performance is

259 further reduced ( $\beta=0.1$ ), natural selection does not drive eusociality (Fig. $4 D$ ), because

260 helpers cannot produce sufficient resources for increased egg production. Most

261 importantly, the level of genomic imprinting is a key factor driving eusociality; the number

262 of generations required for eusociality (or lifelong helper) to evolve sharply decreases

263 with imprinting strength (i.e., epimark transmission rate $\varepsilon$ for a given $E_{t}$ ) (Fig. 4E).

264 Eusociality cannot be achieved if imprinting strength is too low (gray area in Fig. 4E).

265 Also, the development of eusociality is impossible if colony longevity $T$ is too short (Fig.

266 S7), because the contribution of the first brood helpers cannot be used for the production 267 of alates in the colony. It should be noted that when $T$ is larger, it takes more time for 268 eusociality to evolve. This is because it takes more generations for the first brood to 269 become lifelong helpers when they have a longer lifespan $\left(\Phi=T+\tau_{\min }\right)$.

\section{Discussion}

272 The theoretical framework of the present model assumes iteroparity of the founder

273 parents within the nest. This assumption is reasonable because all eusocial insects are

274 iteroparous, which is essential to produce staggered age classes within colonies,

275 enabling older offspring to rear younger siblings. In contrast, the Cryptocercus

276 woodroach (the sister group of termites) is semelparous (Nalepa, 1988) and not

277 eusocial. Without iteroparity (no second nor later brood), the evolutionary feedback loop 
278 cannot be established. Unlike the Hymenoptera where eusociality evolved multiple

279 times, eusociality evolved only once in the cockroaches (termites) around $150 \mathrm{Myr}$ ago

280 (Bourguignon et al., 2015; Legendre et al., 2015). This single origin of eusociality in

281 Blattodea is likely due to the fact that the acquisition of within-nest iteroparity occurred

282 only once in this taxon, although non-nesting and serial nesting iteroparity are known in

283 some species (Trumbo, 2013).

284 The developmental time to reach maturity should have been long in the subsocial

285

286

287

288

289

290

291

292

293

294

295

296

297

298

299

300

301

302

303

304

305

306

307

308

309

310 termite ancestor due to a nitrogen-poor wood diet as in wood-feeding cockroaches in which developmental time ranges from three to seven years (Nalepa, 2015). Among wood-feeding cockroaches, the sister-group of termites, Cryptocercus, is the only known oviparous cockroach with biparental care and altricial development (Bell et al., 2007; Klass et al., 2008) under biparental care, crucial conditions for the origin of eusociality (Nalepa, 2010). The prolonged altricial period of the offspring creates overlapping broods within a colony providing the opportunity for older brood to help younger sibs (Thorne, 1997). We can reasonably expect that in the termite ancestor the presence of older brood was advantageous for the parents and younger sibs because they provided nest excavation, trophallaxis, allogrooming, defense and other forms of brood care. Therefore, we can expect high work performance $\beta$ of the helpers in the subsocial ancestral state. In our model, a certain level of work performance $\beta$ is necessary for the origin of eusociality. Interestingly, however, $\beta$ can be as low as 0.1 when other conditions are favorable (e.g., $T \geq 15, \varepsilon \geq 0.2, F_{0} \geq 20$, Fig. $4 A$ ).

As we discussed at the beginning, the evolutionary mechanisms driving the origin of eusociality and selection for the maintenance and later elaboration of eusociality should be discussed separately. We demonstrated that the acquisition of eusociality promotes the production of alates by a colony and also increases the inclusive fitness of the first brood compared with the initial subsocial state (Fig. $4 B$ and $C$ ). In this respect, our findings are consistent with inclusive fitness theory. Most importantly, however, we found that inclusive fitness theory itself cannot explain the origin of eusociality. During the transition from the subsocial to the eusocial state, inclusive fitness of the first brood results in a zigzag line alternating up and down for levels of fitness (Fig. $4 B$ and $C$ ), because there is a time lag between the origin of a prolonged helper period in the first brood offspring and an increase in the reproductive capacity of the parents to utilize the additional resources. This indicates that selection for higher inclusive fitness of the 
311 offspring cannot get over the selection valley (it goes down and then up again) and thus

312 cannot generate lifelong helpers.

313 The earlier hypothesis that tried to overcome this selection valley is parental

314 manipulation (Alexander, 1974): parents restrict the reproductive options of some

315 offspring so that they assist in the production of fully fertile offspring. A serious problem

316 with this hypothesis is that counter-selection on the offspring would make them

317 overcome parental manipulation. Moreover, this hypothesis also cannot explain the

318 origin of eusociality, although parental manipulation may increase the parental fitness

319 and the inclusive fitness of the sterile workers in a eusocial state. Selection cannot act

320 on the parents a priori in favor of restricting offspring's reproductive development in a

321 subsocial state because it merely reduces the number of fertile offspring and thus their

322 own fitness unless it can be coupled with the subsequent evolution of the ability of the

323 parents to utilize the additional resources for reproduction. A related idea of parental

324 manipulation is the subfertility hypothesis of West-Eberhard (West-Eberhard, 1975),

325 which assumes that subfertile offspring can be produced by inescapable factors such as

326 food shortage and these subfertile offspring would give up reproduction and accept a

327 worker role.

328 Genomic imprinting can be considered one such inescapable factor that produces

329 subfertile offspring. In our genomic imprinting model, natural selection acts on the

330 reproductive capacity of parents so as to increase their direct fitness. Greater

331 reproductive capacity requires higher epigenetic modification of the genes for sexual

332 development (Rice et al., 2016). Sex-specific epigenetic modifications are potential

333 mechanisms underlying sexual dimorphism in various taxa (Hall et al., 2014; Pennell and

334 Morrow, 2013). When sex-specific epimarks that canalize sexually dimorphic

335 development are inherited by the offspring (Rice et al., 2012), sex-antagonistic action

336 (Gadagkar, 2000) of the maternally and paternally inherited epimarks generates the

337 delay of sex expression in the offspring, i.e., the first brood helpers. The offspring's

338 phenotype resulting from the transgenerational epigenetic inheritance is an extended

339 phenotype of the parents, and is thus inescapable for the offspring.

$340 \quad$ Ultimately, whether eusociality spreads in a population depends on the specific

341 benefits of altruistic behavior of the sterile workers relative to their own independent

342 reproduction (Hamilton, 1964). Right at and after the origin of eusociality, the fitness

343 interests of the parents and the offspring coincide with each other (Fig. $4 B$ and C, Fig. 
344 S7): the inclusive (i.e., indirect) fitness of the sterile helpers coincides with the direct

345 fitness of the parents (i.e., colony fitness). From this point on, the subsequent evolution

346 of eusociality is promoted by kin selection, where Hamilton's rule $r>c / b$ is satisfied. In

347 the current numerical analysis, relatedness $r$ is 0.5 because we assume lifelong

348 monogamy of the parents (Boomsma, 2009), and the work performance of helpers $\beta$

349 corresponds to the indirect benefit $b$, while the fitness loss produced by the prolonged

350 helper period $\tau$ is the cost $c$ of helpers. Then kin selection (i.e., colony level selection)

351 drives the evolution of extreme morphology and self-sacrificing behavior of soldiers

352 highly specialized in their defensive tasks (Deligne et al., 1981; Šobotník et al., 2012),

353 sophisticated pheromonal communication regulating caste differentiation (Matsumura et

354 al., 1968; Matsuura et al., 2010, 2007; Mitaka et al., 2017), and loss of totipotency, all of

355 which accelerate the reproductive division of labor.

356 This genomic imprinting theory is based on the fact that genomic imprinting operates

357 in caste determination of termites, where sexual development of the offspring is

358 influenced by the sexual phenotypes of parents via transgenerational epigenetic effects

359 (Matsuura, 2020b; Matsuura et al., 2018). Many molecular agents are known to mediate

360 genomic imprinting such as DNA methylation, histone modifications, noncoding RNAs

361 and transcription factors (Ferguson-Smith, 2011; Reik and Walter, 2001). Sex-specific

362 methylation is a potential mechanism underlying sexual dimorphism in various taxa (Hall

363 et al., 2014; Pennell and Morrow, 2013), and a recent molecular study demonstrated that

364 DNA methylation regulates female fecundity in insects (Zhang et al., 2015). In termites,

365 the level of DNA methylation is known to be considerably higher than in any other social

366 insect studied to date (Glastad et al., 2016). Future studies are needed to determine the

367 exact molecular mechanism underlying the genomic imprinting of termites, even though

368 our conclusion holds irrespective of the exact agents.

369 The current theory to explain the origin of eusociality has the potential for broad

370 applications to the origin of sterile workers in various diploid animals such as the

371 ambrosia beetle Austroplatypus incompertus (Smith et al., 2018) and the naked mole-rat

372 Heterocephalus glaber (Jarvis, 1981). It remains to be investigated in the future whether

373 this theory can be extended to the origin of eusocial Hymenoptera, in which the

374 existence and the role of genomic imprinting in the current caste system are still

375 controversial. This study shows that transgenerational epigenetic inheritance can play a 
376 key role in the inception of eusociality and provides a novel framework for studying the

377 evolution of social systems in various organisms.

378

379 Data Availability.

380 Major simulation data supporting the findings of this study are available within the paper 381 and Supplementary Information. Simulation data can be generated within the custom-

382 made code and the parameter sets provided. Custom-made simulation code is available 383 via GitHub at (https://github.com/ltoHiromu/Eusoc-Sim). Acknowledgments.

386 We thank N.E. Pierce, Y. Iwasa, H. Saze, S. Gavrilets, K. Tsuji, E. Tasaki, T. Ishibashi, 387 N. Mizumoto and M. Takata for discussions of this topic. K.M. acknowledge financial 388 support from JSPS through grant 18H05268, $18 \mathrm{H} 05372$ and 25221206 . E.L.V. was 389 supported by the Urban Entomology Endowment at Texas A\&M University.

\section{References}

Alexander RD. 1974. The evolution of social behavior. Annu Rev Ecol Syst 5:325-383. doi:10.2307/2096892

Bell WJ, Roth LM, Nalepa CA. 2007. Cockroaches: Ecology, Behavior, and Natural History. Baltimore, MD: The Johns Hopkins University Press.

Bonduriansky R, Day T. 2008. Nongenetic inheritance and its evolutionary implications. Annu Rev Ecol Evol Syst 40:103-125.

397 Boomsma JJ. 2009. Lifetime monogamy and the evolution of eusociality. Philos Trans $R$ Soc Lond B Biol Sci 364:3191-3207.

399 Bourguignon T, Lo N, Cameron SL, Šobotník J, Hayashi Y, Shigenobu S, Watanabe D, 400 Roisin Y, Miura T, Evans TA. 2015. The evolutionary history of termites as 
inferred from 66 mitochondrial genomes. Mol Biol Evol 32:406-421. doi:10.1093/molbev/msu308

403 Chong S, Whitelaw E. 2004. Epigenetic germline inheritance. Curr Opin Genet Dev 14:692-696. doi:10.1016/j.gde.2004.09.001

405 Cleveland LR, Hall SR, Sanders ER, J. C. 1934. The wood-feeding roach Cryptocercus punctulatus, its protozoa, and the symbiosis between protozoa and roach. Memoirs of the American Academy of Arts and Sciences 17:185-342.

Darwin C. 1859. On the Origin of Species by Means of Natural Selection, or the Preservation of Favoured Races in the Struggle for Life. London: John Murray.

Deligne J, Quennedey A, Blum MS. 1981. The enemies and defense mechanisms of termites In: Hermann HR, editor. Social Insects Vol.2. New York: Academic Press New York. pp. 1-76.

413 Ferguson-Smith AC. 2011. Genomic imprinting: the emergence of an epigenetic paradigm. Nat Rev Genet 12:565-575. doi:10.1038/nrg3032

Gadagkar R. 2000. Do our maternal and paternal genes pull us in different directions? Curr Sci 78:376-380.

417 Glastad KM, Gokhale K, Liebig J, Goodisman MAD. 2016. The caste- and sex-specific DNA methylome of the termite Zootermopsis nevadensis. Sci Rep 6:37110.

420 Hall E, Volkov P, Dayeh T, Esguerra JL ou S, Salö S, Eliasson L, Rönn T, Bacos K, Ling C. 2014. Sex differences in the genome-wide DNA methylation pattern and 

pancreatic islets. Genome Biol 15:522. doi:10.1186/s13059-014-0522-z

424 Hamilton WD. 1964. The genetical evolution of social behaviour. I, II. J Theor Biol 7:152.

426 Hölldobler B, Wilson EO. 2009. The superorganism: the beauty, elegance, and strangeness of insect societies. WW Norton \& Company.

428 Jablonka E, Raz G. 2009. Transgenerational epigenetic inheritance: prevalence, 429 mechanisms, and implications for the study of heredity and evolution. Q Rev Biol $430 \quad 84: 131-176$. doi:10.1086/598822

431 Jacob F. 1977. Evolution and tinkering. Science.

432 Jarvis JUM. 1981. Eusociality in a mammal: Cooperative breeding in naked mole-rat $433 \quad$ colonies. Science 212:571-573. doi:10.1126/science.7209555

434 Kay T, Keller L, Lehmann L. 2020. The evolution of altruism and the serial rediscovery of the role of relatedness. Proc Natl Acad Sci U S A 117:28894-28898.

437 Klass KD, Nalepa CA, Lo N. 2008. Wood-feeding cockroaches as models for termite evolution (Insecta : Dictyoptera): Cryptocercus vs. Parasphaeria boleiriana. Mol Phylogenet Evol 46:809-817. doi:10.1016/j.ympev.2007.11.028

440 Korb J. 2008. The ecology of social evolution in termitesEcology of Social Evolution. doi:10.1007/978-3-540-75957-7_7

442 Legendre F, Nel A, Svenson GJ, Robillard T, Pellens R, Grandcolas P. 2015. Phylogeny 443 of dictyoptera: Dating the origin of cockroaches, praying mantises and termites 
$444 \quad$ with molecular data and controlled fossil evidence. PLoS One 10:1-27.

445 doi:10.1371/journal.pone.0130127

446 Matsumura F, Coppel HC, Tai A. 1968. Isolation and identification of termite trail-

447 following pheromone. Nature 219:963-964.

448 Matsuura K. 2020a. Epigenetic inheritance and a paradigm shift in evolutionary ecology.

$449 \quad$ Popul Ecol 62:15-16. doi:10.1002/1438-390x.12034

450 Matsuura K. 2020b. Genomic imprinting and evolution of insect societies. Popul Ecol

$451 \quad$ 62:38-52. doi:10.1002/1438-390x.12026

452 Matsuura K. 2017. Evolution of the asexual queen succession system and its underlying 453 mechanisms in termites. J Exp Biol 220:63-72. doi:10.1242/jeb.142547

454 Matsuura K, Himuro C, Yokoi T, Yamamoto Y, Vargo EL, Keller L. 2010. Identification of 455 a pheromone regulating caste differentiation in termites. Proc Natl Acad Sci U S $456 \quad$ A 107:12963-12968. doi:10.1073/pnas.1004675107

457 Matsuura K, Mizumoto N, Kobayashi K, Nozaki T, Fujita T, Yashiro T, Fuchikawa T, 458 Mitaka Y, Vargo EL. 2018. A genomic imprinting model of termite caste 
determination: Not genetic but epigenetic inheritance influences offspring caste fate. Am Nat 191:677-690. doi:10.1086/697238

Matsuura K, Tamura T, Kobayashi N, Yashiro T, Tatsumi S. 2007. The antibacterial protein lysozyme identified as the termite egg recognition pheromone. PLoS One 2:e813. doi:10.1371/journal.pone.0000813

Matsuura K, Vargo EL, Kawatsu K, Labadie PE, Nakano H, Yashiro T, Tsuji K. 2009. Queen succession through asexual reproduction in termites. Science 323:1687. doi:10.1126/science.1169702

Mitaka Y, Mori N, Matsuura K. 2017. Multi-functional roles of a soldier-specific volatile as a worker arrestant, primer pheromone and an antimicrobial agent in a termite. Proc $R$ Soc B 284:20171134. doi:10.1098/rspb.2017.1134

Müller GB, Wagner GP. 1991. Novelty in evolution: Restructuring the concept. Annu Rev Ecol Syst 22:229-256. doi:10.1146/annurev.es.22.110191.001305

Nalepa CA. 2015. Origin of termite eusociality: Trophallaxis integrates the social, nutritional, and microbial environments. Ecol Entomol 40:323-335. doi:10.1111/een.12197

Nalepa CA. 2010. Altricial development in subsocial cockroach ancestors: foundation for

Nalepa CA. 1994. Nourishment and the origin of termite eusociality In: Hunt JH, Nalepa the evolution of phenotypic plasticity in termites. Evol Dev 12:95-105. doi:10.1111/j.1525-142X.2009.00394.x CA, editors. Nourishment and Evolution in Insect Societies. Boulder, CO, USA: Westview Press. pp. 57-104.

Nalepa CA. 1988. Cost of parental care in the woodroach Cryptocercus punctulatus Scudder (Dictyoptera: Cryptocercidae). Behav Ecol Sociobiol 135-140.

Nalepa CA. 1984. Colony composition, protozoan transfer and some life history characteristics of the woodroach Cryptocercus punctulatus Scudder (Dictyoptera: Cryptocercidae). Behav Ecol Sociobiol 14:273-279. doi:10.1007/BF00299498

Nowak MA, Tarnita CE, Wilson EO. 2010. The evolution of eusociality. Nature 466:1057-1062. doi:10.1038/nature09205 
488 Pál C, Miklós I. 1999. Epigenetic Inheritance, Genetic Assimilation and Speciation. J Theor Biol 200:19-37. doi:10.1006/jtbi.1999.0974

490 Pennell TM, Morrow EH. 2013. Two sexes, one genome: The evolutionary dynamics of intralocus sexual conflict. Ecol Evol 3:1819-1834. doi:10.1002/ece3.540

492 Reik W, Walter J. 2001. Genomic imprinting: parental influence on the genome. Nat Rev Genet 2:21-32. doi:10.1038/35047554

494 Rice WR, Friberg U, Gavrilets S. 2016. Sexually antagonistic epigenetic marks that canalize sexually dimorphic development. Mol Ecol 25:1812-1822.

Rice WR, Friberg U, Gavrilets S. 2012. Homosexuality as a consequence of epigenetically canalized sexual development. Q Rev Biol 87:343-368.

Smith SM, Kent DS, Boomsma JJ, Stow AJ. 2018. Monogamous sperm storage and permanent worker sterility in a long-lived ambrosia beetle. Nature Ecology and Evolution 2:1009-1018. doi:10.1038/s41559-018-0533-3

Šobotník J, Bourguignon T, Hanus R, Demianová Z, Pytelková J, Mareš M, Foltynová P, Preisler J, Cvačka J, Krasulová J, Roisin Y. 2012. Explosive backpacks in old termite workers. Science 337:436. doi:10.1126/science.1219129

West-Eberhard M. 1975. The evolution of social behavior by kin selection. Q Rev Biol 50:1-33.

Wilson EO. 1971. The insect societies. Cambridge, MA: Harvard University Press.

Wilson EO, Hölldobler B. 2005. Eusociality: Origin and consequences. Proc Natl Acad Sci U S A 102:13367-13371. doi:10.1073/pnas.0505858102 essential role in female fecundity in brown planthopper, Nilaparvata lugens. Biochem Biophys Res Commun 464:83-88. doi:10.1016/j.bbrc.2015.05.114 


\section{Figures}

A

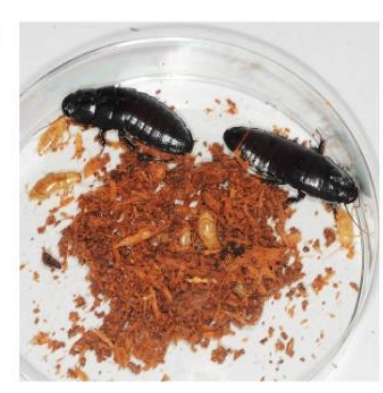

B

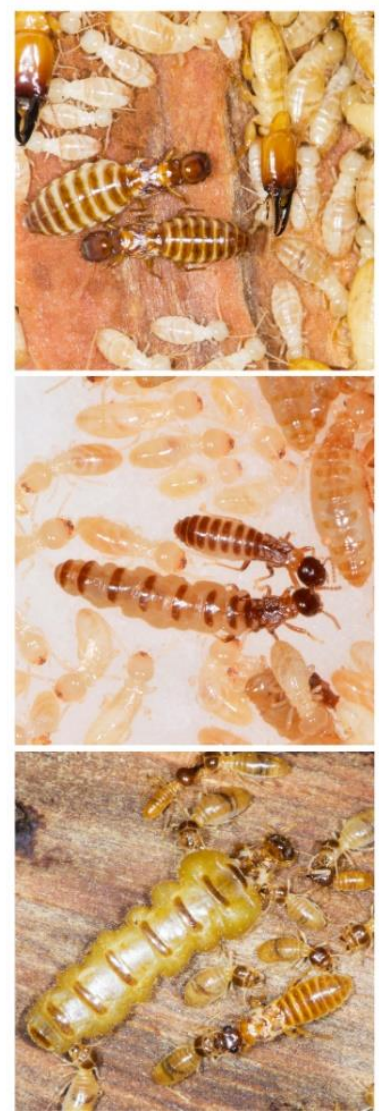

E
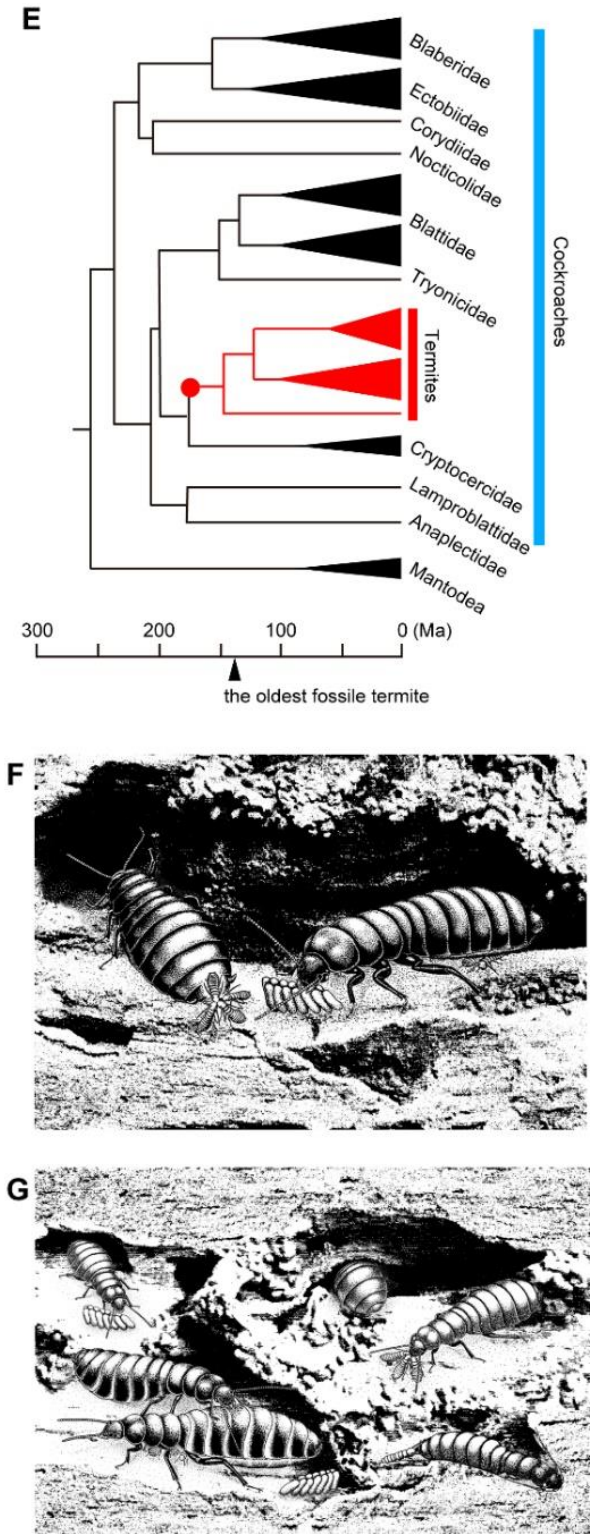

Figure 1. Termite eusociality originated from a lineage of subsocial woodroach. (A) Monogamy in a woodroach Cryptocercus punctulatus, which is an oviparous cockroach with biparental care. $(B-D)$ A primary king $(\mathrm{PK})$ and a primary queen (PQ) of a damp-wood termite Zootermopsis nevadensis, a subterranean termite Reticulitermes speratus and a higher termite Nasutitermes takasagoensis, respectively. ( $E$ ) Phylogenetic placement of termites. Termites are a sister group of Cryptocercidae. $(F$, $G)$ Imaginary illustration of the incipient colony $(F)$ and a developed family $(G)$ of the first termite. The founder female produces a packaged egg mass as in the basal termite Mastotermes darwiniensis. The first brood helpers contribute to the production of younger sibs through wood excavation, trophallaxis, allogrooming, nest hygiene and so on. Photos by K.M. Illustrations by H.O and K.M. 
A

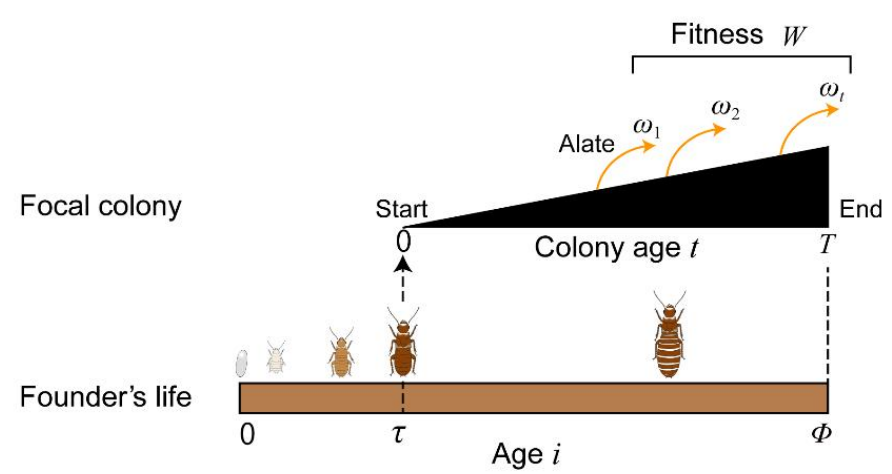

B

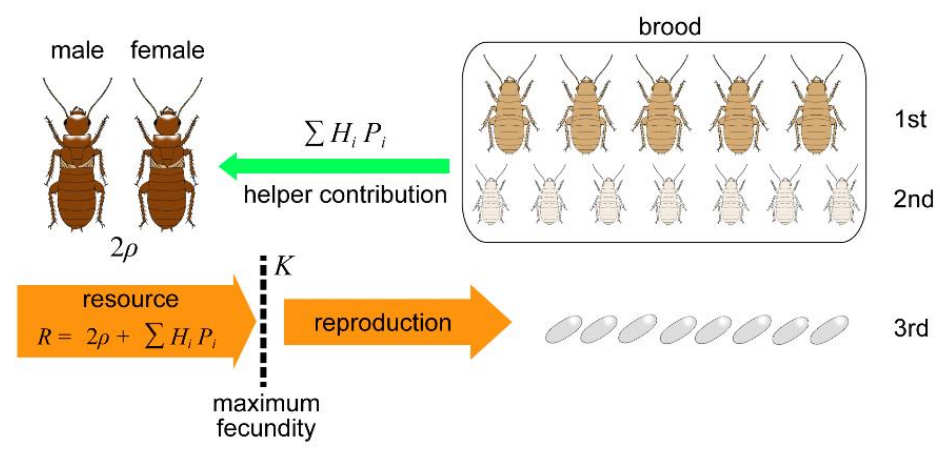

C
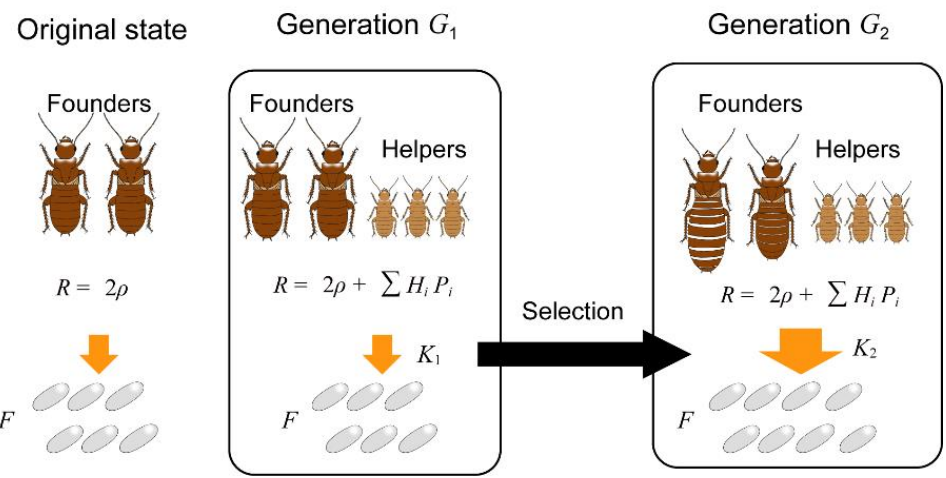

Figure 2. Schematic view of the model life cycle of a subsocial ancestor of termites just before the origin of eusociality. $(A)$ Colony life cycle. Individuals become alates (imagoes) and leave their natal nest at age $\tau$. They disperse and establish new colonies by pairing with an unrelated individual. The colony produces alates $\omega_{t}$ at colony age $t$. Total number of alates produced $W$ during the colony lifespan $(\Phi-\tau)$ is defined as the fitness of the focal colony. (B) Presence of older brood in the nest contributes to resource acquisition of parents. (C), Additional resources can be a selective force for the evolution of higher fecundity of founders. Without helpers, the founders reproduce by using their own resources $2 \rho$ (left). Even if there were additional resources from the helpers' contributions, the founders would not be able to use them for reproduction due to the upper limit of their fecundity $K_{1}$ (center). Selection favors higher fecundity $K_{2}$ of the founders so as to fully utilize the additional resources for reproduction 

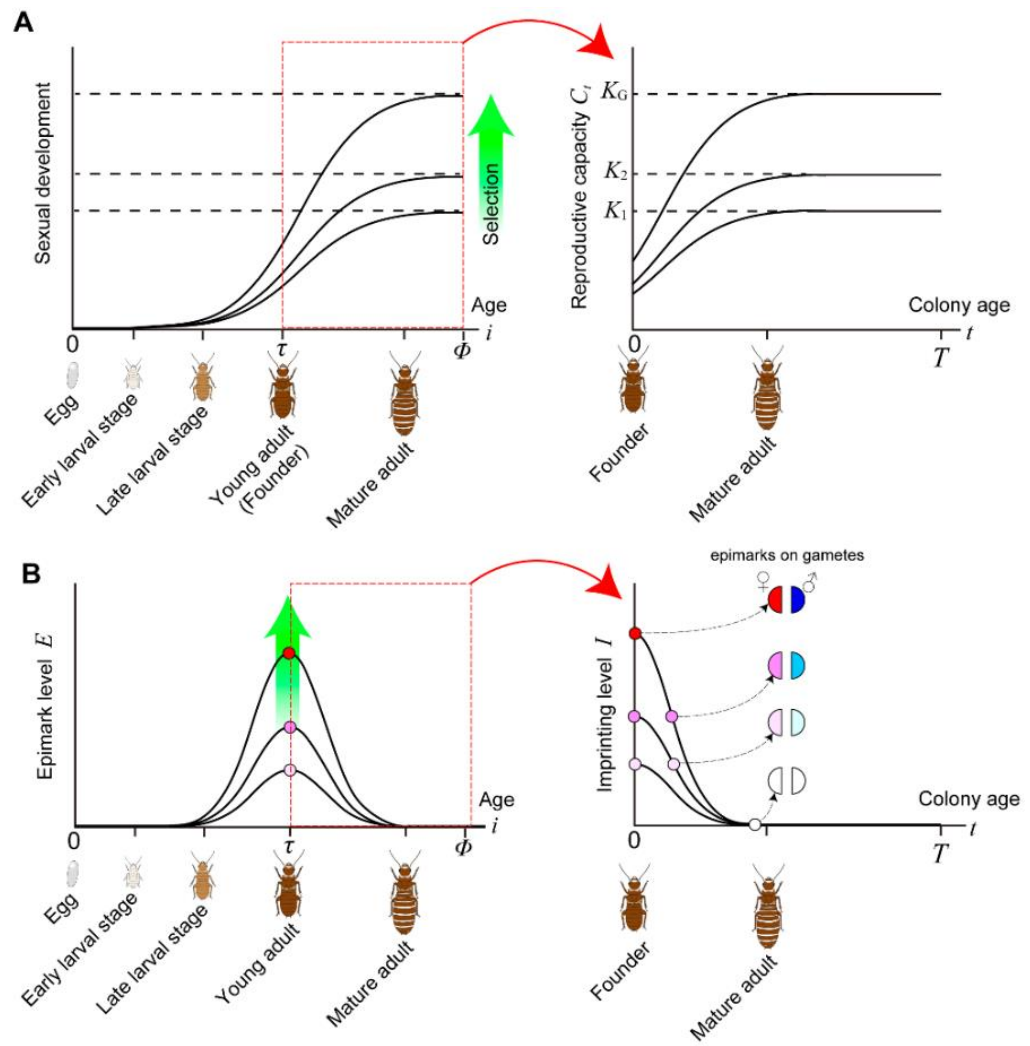

C
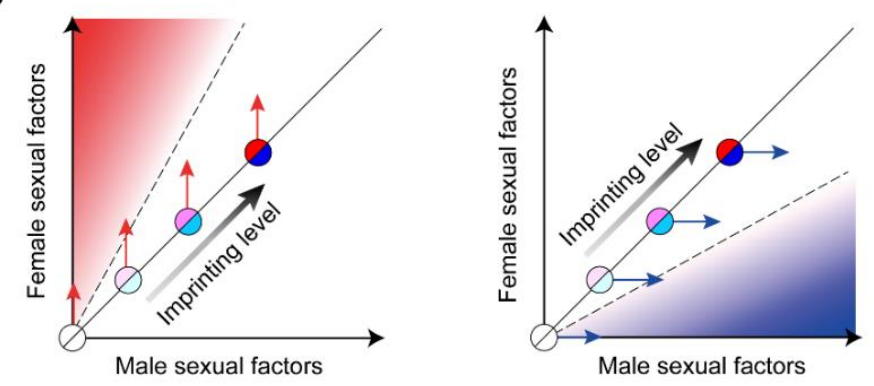

547 Figure 3. The genomic imprinting model for the origin of eusociality. Sex-

548 antagonistic action of maternally- and paternally-inherited epimarks retains the offspring

549 in the neuter state. (A) Sexual development of individuals (left) and reproductive capacity 550 of founders $C_{t}$ (right). (B) Development of epimarks in relation to sexual development of 551 the parents (left) and unerased sex-specific epimarks that carryover to the next 552 generation through gametes (right). Reproductive capacity of the parents $C_{t}$ is acquired 553 through canalization of the expression of sexual development genes through epigenetic 554 modification $E_{t}$. Therefore, $E_{t}$ is expressed as the derivative of $C_{t}, E_{t}=\frac{d C_{t}}{d t}$. Blue and 555 red semicircles indicate paternally- and maternally-inherited epimarks, respectively. 556 Darkness of the color represents the strength of epimarks. (C) Antagonistic action of 557 maternal and paternal imprinting in the offspring. Illustrations by K.M. 
A
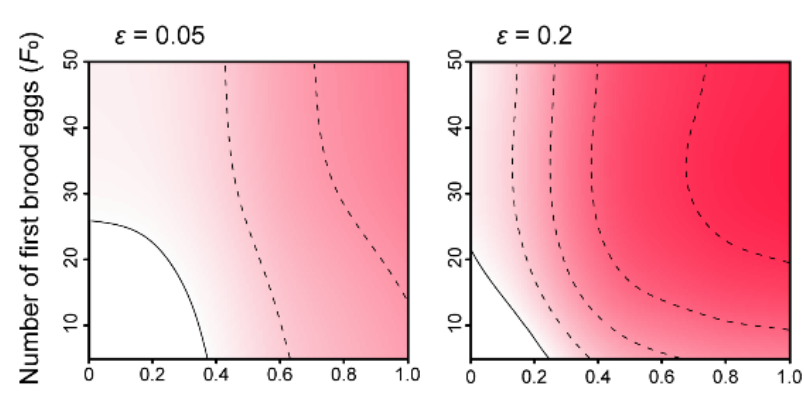

Relative work performance $(\beta)$

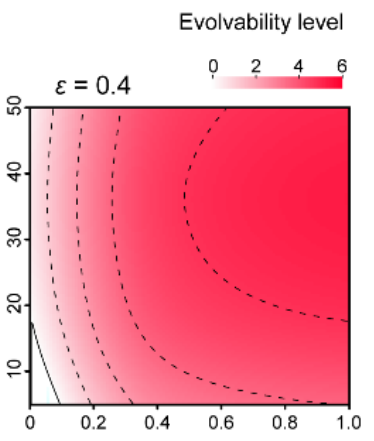

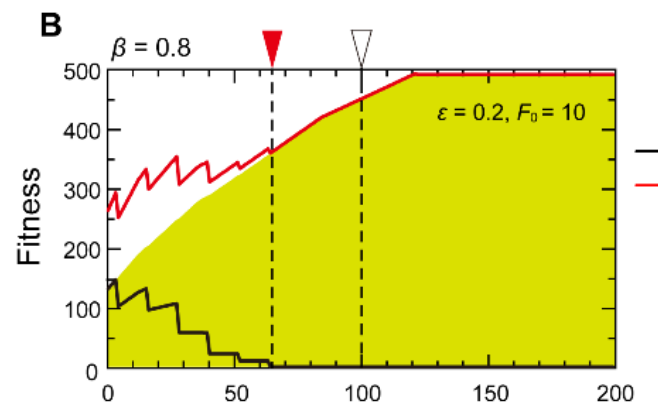
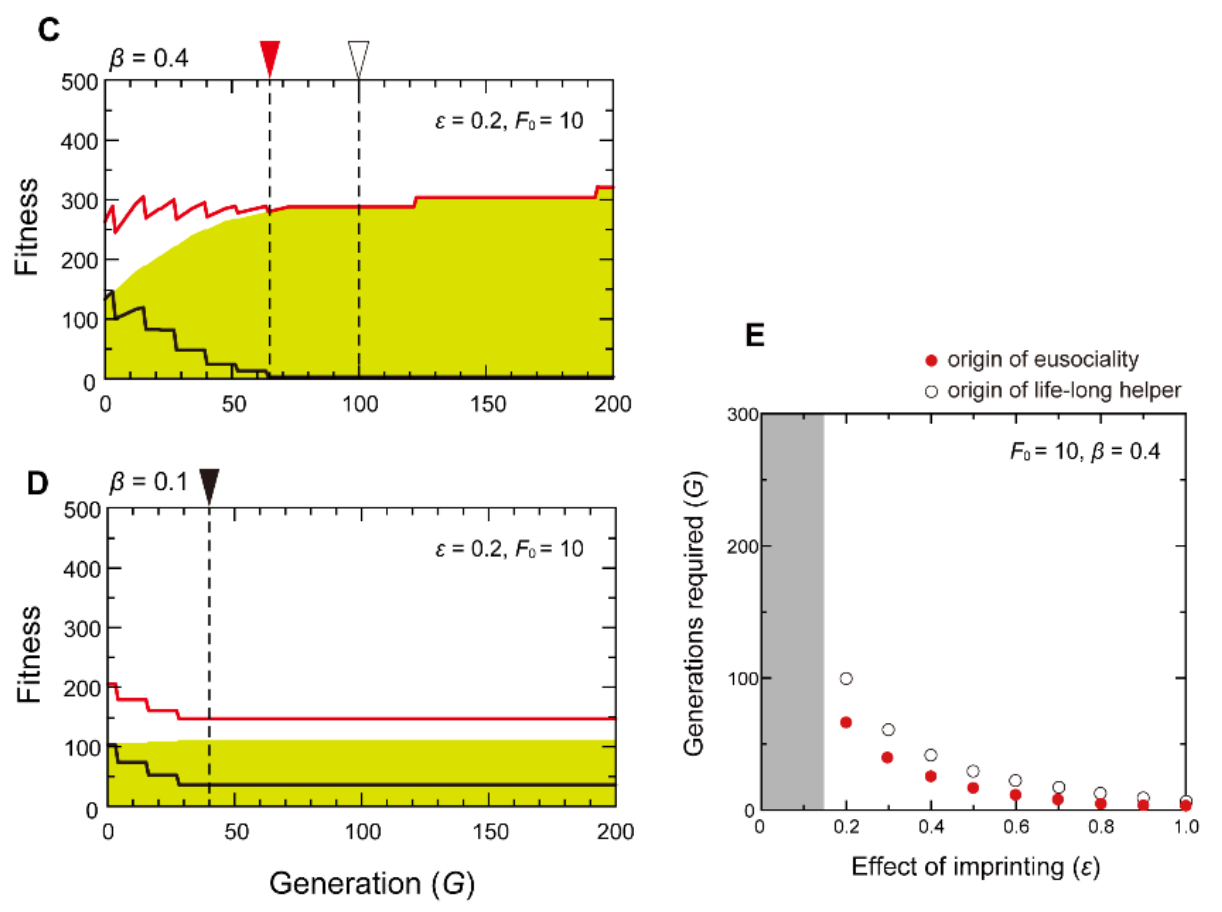

Figure 4. Evolvability of eusociality. ( $A$ ) The effect of work performance of helpers $\beta$ and initial fecundity of the parents $F_{0}$ on the evolvability of eusociality. Eusociality is easily achieved under high epimark transmission rate $\varepsilon$ and/or high work performance of helpers $\beta$. Evolvability level is evaluated by the level of eusociality acquisition (indicated by the intensity of red color) when colony longevity $T$ is varied from 10 to 15 years (Level 0 : no acquisition; level 6: acquisition under all $T$ cases). Eusociality acquisition is defined as the appearance of a helper with no direct fitness (inclusive fitness only). (B-D) Fitness 
566 dynamics of the parents and the first brood offspring under different work performance

567 levels of helpers $\beta\left(T=13, \varepsilon=0.2, F_{0}=10\right)$. Green area indicates the direct fitness of 568 parents (the number of alates produced by a colony). Black and red lines indicate the 569 direct and inclusive fitness of the first brood, respectively. Red arrowheads indicate the 570 origin of eusociality (the appearance of a helper with no direct fitness). Open arrowheads 571 indicate the appearance of a lifelong helper. Black arrowheads indicate the point when 572 selection stops, i.e., the direct fitness of the parents decreases from that of the previous 573 generation in numerical calculation. $(E)$ Effect of genomic imprinting level $I_{t}$ (i.e., $\varepsilon$ for a 574 given $E_{t}$ ) on the generation required to reach eusociality. Red and open circles indicate 575 the origin of eusociality and the appearance of a lifelong helper, respectively. Gray area 576 indicates the region where eusociality is not achieved. 


\section{Supplementary Information for}

\section{Genomic imprinting drives eusociality}

Kenji Matsuura',\#^, Hiromu Ito ${ }^{2, \#, ~ K a z u y a ~ K o b a y a s h i ~}{ }^{3}$, Haruka Osaki $^{4}$, Jin Yoshimura$^{2}$, Edward L. Vargo 5

${ }^{1}$ Laboratory of Insect Ecology, Graduate School of Agriculture, Kyoto University, Kyoto, Japan. ${ }^{2}$ Department of International Health and Medical Anthropology, Institute of Tropical Medicine, Nagasaki University. Nagasaki, Japan. ${ }^{3}$ Hokkaido Forest Research Station, Field Science Biology, Kyushu University, Fukuoka, Japan. ${ }^{5}$ Department of Entomology, Texas A\&M University,

589 *Kenji Matsuura

590 Email: matsuura.kenji.6s@kyoto-u.ac.jp

This PDF file includes:

Supplementary text

1. Transgenerational epigenetic inheritance; a paradigm shift in biology

2. Genomic imprinting as a carryover effect of parental epimarks

3. Asexual queen succession in termites

4. Genomic imprinting in termites 


\section{Backgrounds}

We here introduce the latest studies on the transgenerational epigenetic inheritance and genomic imprinting in termites following the recent review by Matsuura (Matsuura, 2020).

\section{Transgenerational epigenetic inheritance; a paradigm shift in biology}

Evolution by natural selection requires phenotypic variation, inheritance and selection forces. Charles Darwin conceived the theory of natural selection without knowing the agent of inheritance. Biology is traditionally dominated by the idea of genetic determinism, which is focused almost exclusively on genetic inheritance and processes that change gene frequencies. Recent empirical studies have convincingly demonstrated transgenerational epigenetic inheritance in various eukaryotic organisms including yeasts (Grewal and Klar, 1996), plants (Hauser et al., 2011; Miryeganeh and Saze, 2020) nematodes (Remy, 2010; Serobyan and Sommer, 2017), mammals (Daxinger and Whitelaw, 2012; Perez and Lehner, 2019) and insects (Mukherjee and Vilcinskas, 2019). The transfer of epigenetic marks from parents to offspring can influence offspring phenotype independent of the DNA sequence (Bonduriansky and Day, 2008). The concept of epigenetic inheritance provides solutions for many previously-unsolved puzzles by circumventing the limitation of genetic inheritance (Bonduriansky and Day, 2008; Jablonka and Raz, 2009; Szyf, 2014). Theoretical studies indicate that epigenetic inheritance is an important factor in evolution that can produce outcomes that are not anticipated under traditional genetics. Therefore, it is apparent that biology is in a major transitional period that will take it forward from the previously narrow perspective.

Over the past decade there has been a rapid accumulation of definitive evidence for the molecular mechanisms underlying transgenerational epigenetic inheritance (Greer and Shi, 2012; Liberman et al., 2019; Martin and Zhang, 2007; Miska and Ferguson-smith, 2016; Moazed, 2011). In principle, any molecular change in the zygote other than alterations in DNA sequence could carry non-genetic information including DNA methylation, histone modification, non-coding RNA, prions and microbiota.

\section{Genomic imprinting as a carryover effect of parental epimarks}

The effects of transgenerational epigenetic inheritance on offspring are often sex-specific (Bonduriansky and Day, 2008; Vigé et al., 2008). A phenomenon related to transgenerational epigenetic inheritance is genomic imprinting, whereby epimark transmission depends on parental sex, resulting in parent-of-origin allelic expressions (Gregg et al., 2010; Lawson et al., 2013; Xu et al., 2014). Recent evidence also suggests that imprinting effects can depend on offspring sex (Hager et al., 2008).

Kinship theory of genomic imprinting focuses on a conflict (Haig, 2014) between the maternal and paternal genes (see also Holman \& Kokko (Holman and Kokko, 2014) and Patten et al. (Patten et al., 2014)). Genomic imprinting can occur as a by-product of another advantageous process such as retrotransposon silencing (Suzuki et al., 2007) or canalization of sexually dimorphic development (Rice et al., 2012) even if imprinting itself has no fitness advantage. The most parsimonious mechanistic explanation for the origin of genomic imprinting would be incomplete erasure of epigenetic modifications, i.e., carryover effects of parental epimarks (Chong and Whitelaw, 2004; Kearns et al., 2000; Rice et al., 2016). Although epigenetic modifications acquired by parents are mostly erased during gametogenesis, which allows reestablishment of epigenetic marks in the next generation, a portion of epigenetic modifications can be inherited through the germline in a wide variety of taxa including mammals (Anway et al., 
655 2005; Morgan and Bale, 2011), insects (Cavalli and Paro, 1998), yeast (Grewal and Klar, 1996)

656 and plants (Miryeganeh and Saze, 2020).

The degree of sexual dimorphism will be associated with the degree of sex-specific igenetic modifications (Deegan and Engel, 2019). Selection favoring a higher degree of sexual dimorphism would lead to a higher imprinting level, if the efficiency of erasure is not changed. This carryover effect of sex-specific parental epimarks on the offspring's development can contribute to the determination of the phenotype (Matsuura et al., 2018; Rice et al., 2013, 2012).

\section{Asexual queen succession in termites}

Transgenerational epigenetic inheritance and genomic imprinting have been attracting more and more attention in the study of insects because many phenomena involving non-genetic inheritance have been found in a number of insect species (Galbraith et al., 2016; Gegner et al., 2019; Matsuura, 2020; Mukherjee and Vilcinskas, 2019). In particular, the effects of parental phenotypes on the caste fate of offspring have been discovered in termites, which provides definitive evidences for non-genetic inheritance (Matsuura et al., 2018). A unique reproductive system named Asexual Queen Succession (AQS) has been identified in several termite species, in which workers, soldiers and alates are produced sexually while neotenic queens arise through thelytokous parthenogenesis and eventually replace the old queens (Hellemans and Roisin, 2020; Matsuura, 2017; Matsuura et al., 2009) (Fig. S1). Then, neotenic queens are replaced by subsequent cohorts of asexually-produced neotenic queens. Therefore, as long as the colonies survive, the queens are genetically immortal. This is advantageous for both the queens and other colony members because queens can boost reproduction without inbreeding.

After the first report of AQS in the Japanese subterranean termite $R$. speratus (Matsuura et al., 2009), AQS has been continuously found in other Reticulitermes species in other continents: $R$. virginicus in the US (Vargo et al., 2012) and R. lucifugus in Italy (Luchetti et al., 2013). Timescaled phylogeny of the genus Reticulitermes demonstrated that AQS was absent in the basal lineage but has evolved at least three times independently, in East Asia (ca. 7-5 million years ago), in West Europe (ca. 10-5 million years ago) and in North America (less than 14.1 million years ago) (Dedeine et al., 2016). Recent surveys of the breeding systems of higher termites (Termitidae) in French Guiana have repeatedly identified AQS in Neotropical termitids including Embiratermes neotenicus (Syntermitinae) (Fougeyrollas et al., 2015), the humivorous termite Cavitermes tuberosus (Termitinae) (Fournier et al., 2016), Silvestritermes minutus (Syntermitinae) (Fougeyrollas et al., 2017) and Palmitermes impostor (Termitinae) (Hellemans et al., 2019). In all of these seven AQS species, the asexual neotenic queens derive from nymphs, i.e., the sexual pathway.

Why has AQS evolved repeatedly in phylogenetically distant lineages? The origin of AQS requires the simultaneous evolution of two distinct traits: parthenogenetic capacity and the developmental priority for parthenogenetic daughters to develop into secondary queens. Then a question emerges as to why parthenogenetic daughters and sexually-produced daughters differ in their developmental propensity. Nozaki et al. (2018) asked if in a non-AQS species, $R$. okinawanus, the female offspring produced by tychoparthenogenesis (i.e., occasional parthenogenesis) differentiate into secondary queens (Nozaki et al., 2018). Interestingly a significantly higher proportion of parthenogenetic daughters developed into neotenic queens (nymphoid queens) than sexually produced females (Nozaki et al., 2018). This suggest that the developmental propensity of parthenogenetic daughters to become neotenic queens existed prior to the origin of AQS, which could explain why AQS evolved repeatedly in phylogenetically distant 701 lineages. 


\section{Genomic imprinting in termites}

Influence of parental phenotypes on the caste fate of offspring is known in the genus Reticulitermes (Hayashi et al., 2007; Kitade et al., 2010). For instance, the daughters produced by queens' parthenogenesis and the daughters produced by the mating of nymph-derived queens and worker-derived males develop exclusively into nymphs. On the other hand, most of the daughters produced by the mating of worker-derived queens and nymph-derived males develop into workers. The theory of genomic imprinting explains the effects of parental phenotypes on caste fate of the offspring(Matsuura et al., 2018). Its prediction matches exactly with empirical data from both lab and field studies.

As shown in the scheme (Fig. S2), the theory of genomic imprinting consists of two stages: 1) development of phenotype-specific parental epimarks and 2) influence of parental imprinting on the development of offspring. Nymph-derived reproductives obtain higher levels of epimarks so as to canalize expression of sexual characters than ergatoids (worker-derived reproductives) (Fig. $\mathrm{S} 2 A)$. Then the maternally- and paternally-inherited epimarks influence the relative expression of growth regulatory genes ( $\varepsilon_{g}$ : growth factors) to sex regulatory genes $\left(\varepsilon_{s}\right.$ : sexual factors), and thus determine the caste fate of offspring (Fig. S2B). Growth with sexual development directs individuals to the sexual pathway (nymphs), while growth without sexual development restricts individuals to the neuter caste (workers). The double maternal imprinting of parthenogenetic daughters leads them to the sexual pathway in AQS species.

The predictions of genomic imprinting model match well both with the caste differentiation patterns of the AQS species $R$. speratus (Hayashi et al., 2007) (Fig. S2B) and those of the nonAQS species $R$. kanmonensis, R. yaeyamanus and R. okinawanus (Kitade et al., 2010). Genomic imprinting clearly explains why the daughters carrying only maternal chromosomes have the developmental propensity to become neotenic queens rather than daughters carrying both paternal and maternal chromosomes.

Genomic imprinting explains why parthenogens carrying only maternal chromosomes preadaptively have the epigenetic and thus developmental advantage to become neotenic queens (Matsuura et al., 2018; Nozaki et al., 2018). Many factors are known to mediate genomic imprinting such as DNA methylation, histone modifications, noncoding RNAs and transcription factors (Ferguson-Smith, 2011; Reik and Walter, 2001). The DNA methylation levels in termites are considerably higher than other hemimetabolous insects (Harrison et al., 2018). Moreover, termites shows caste- and sex-specific DNA methylation patterns (Glastad et al., 2016). The DNA methyltransferases DNMT1 and DNMT3 are known to be involved in maintenance of and mediating de novo DNA methylation, respectively (Goll and Bestor, 2005; Yan et al., 2015). RNAseq analysis of $R$. speratus revealed sex- and caste-dependent expression patterns of the DNA methyltransferases, where alates have higher expression of Dnmt 1 than workers in females but not in males. Alates also showed significantly higher expression of Dnmt3 than workers in males but not in female (Mitaka et al., 2020). These results seem to support the theory of genomic imprinting.

\section{Additional model explanation}

Work performance of helpers. Within-nest iteroparity creates the overlapping broods within a colony, which provides the opportunity for older brood to contribute to the production and growth of younger sibs (Thorne, 1997). The presence of older brood is advantageous for the parents and younger sibs rather than imposing a deleterious effect because they provide nest excavation, trophallaxis, allogrooming, defense and other forms of brood care. Therefore, we can reasonably expect a high work performance $\beta$ of the helpers in the subsocial ancestral state.

Work performance $P_{i}$ (J/year) of a helper offspring increases with age $i$. Eggs (0-year-old) and 1-year-old larvae cannot contribute to social labor. Offspring older than 5-years achieve their 
752 maximum possible performance $\beta \cdot \rho$, where $\beta$ is the relative work efficiency of helpers compared

753 to the work performance of a parent $\rho$. If $\beta$ is 1 , mature helpers have the same work performance 754 as a parent. 2-4 year old offspring have intermediate performance. Thus the helper performance $755 P_{i}$ of a helper at age $i$ (year) is given by (Fig. S3)

756

$757 \quad P_{i}=\left\{\begin{array}{lr}0 & (i=0) \\ \frac{\beta \rho(i-1)}{4} & (1 \leq i \leq 5) \\ \beta \rho & (i>5)\end{array}\right.$

758

759

760 We also investigated the effect of the curvatures $s$ of age-dependent increase in work 761 performance $P_{i}$ on the origin of eusociality (Fig. S4),

762

763

$P_{i}= \begin{cases}0 & (i=0,1) \\ \frac{\beta \cdot \rho}{4}(1-s) & (i=2) \\ \frac{\beta \cdot \rho}{2} & (i=3) \\ \frac{\beta \cdot \rho}{4}(3+s) & (i=4) \\ \beta \cdot \rho & (5 \leq i)\end{cases}$

764

765

There is no qualitative change in the outcome when the curvatures $s$ varies from 0 to 1 (the 766 results were omitted). 
bioRxiv preprint doi: https://doi.org/10.1101/2021.04.28.441822; this version posted April 29, 2021. The copyright holder for this preprint (which was not certified by peer review) is the author/funder, who has granted bioRxiv a license to display the preprint in perpetuity. It is made available under aCC-BY 4.0 International license.

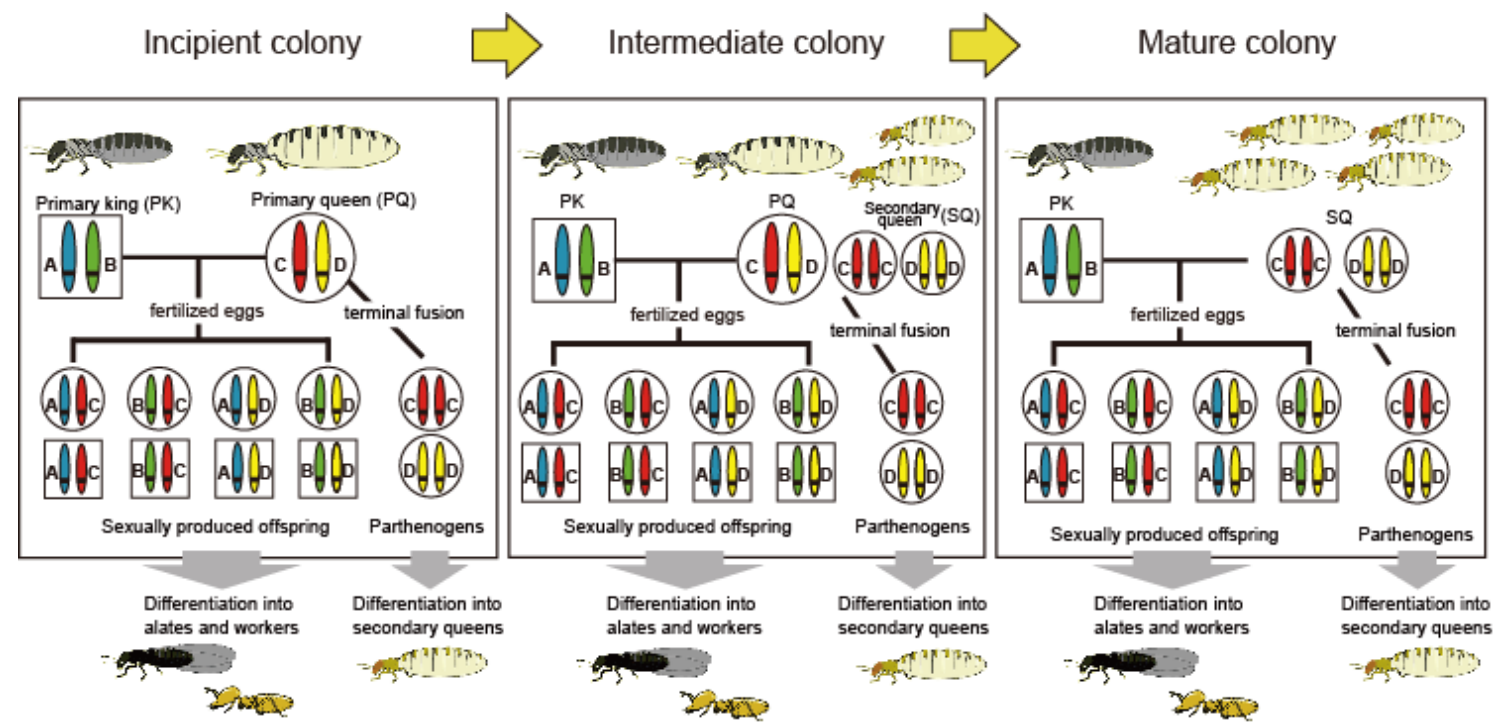

Fig. S1. Asexual queen succession in termites. Secondary queens produced asexually by the primary queen differentiate within the colony and supplement egg production, eventually,

776

777 replacing the primary queen (Matsuura, 2017; Matsuura et al., 2009). This breeding system

778 enables the primary queen to maintain her full genetic contribution to the next generation, while avoiding any loss in genetic diversity from inbreeding. 
bioRxiv preprint doi: https://doi.org/10.1101/2021.04.28.441822; this version posted April 29, 2021. The copyright holder for this preprint (which was not certified by peer review) is the author/funder, who has granted bioRxiv a license to display the preprint in perpetuity. It is made available under aCC-BY 4.0 International license.

780

A

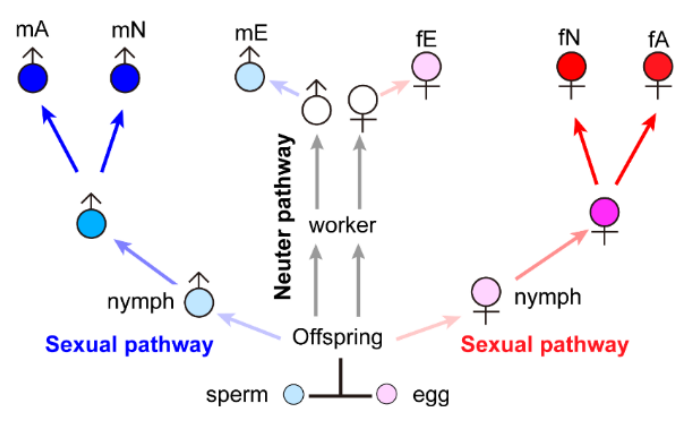

B

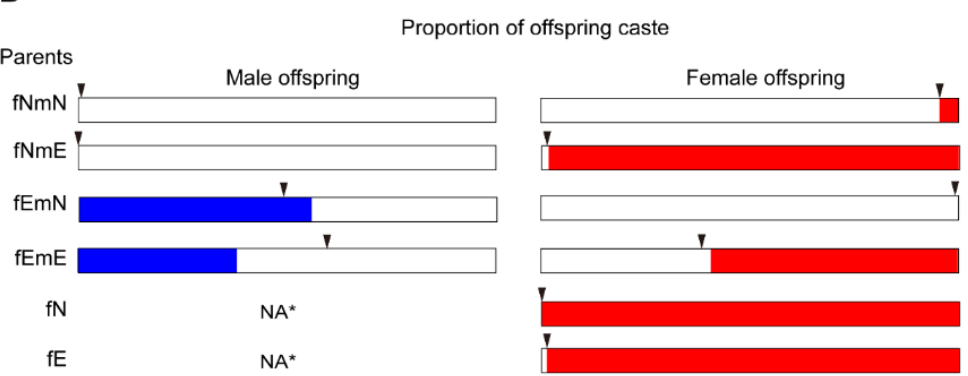

NA*

Fig. S2. Genomic imprinting and caste determination in termites. $(A)$ Caste differentiation $\mathrm{mN}$; female: $\mathrm{fN}$ ) develop with the full canalization of sexual development, while ergatoids (male: $\mathrm{mE}$; female: $\mathrm{fE}$ ) develop by a single sexual molt. Blue and red arrows indicate the development of male- and female-specific epimarks, respectively, and darkness of the color represents the strength of epimarks. $(B)$ Combination of parental phenotypes and outcome of offspring caste (e.g., fEmN: female ergatoid and male nymphoid). The caste differentiation patterns predicted by the genomic imprinting model (bar graphs) and the empirical results (arrowheads) of $R$. speratus (Hayashi et al., 2007). *Parthenogenesis produces only female offspring. Expression levels of growth regulatory genes $\left(\varepsilon_{g}\right)$ and sexual regulatory genes $\left(\varepsilon_{s}\right)$ of the male- and female-offspring. Modified from Matsuura et al. (Matsuura et al., 2018). 


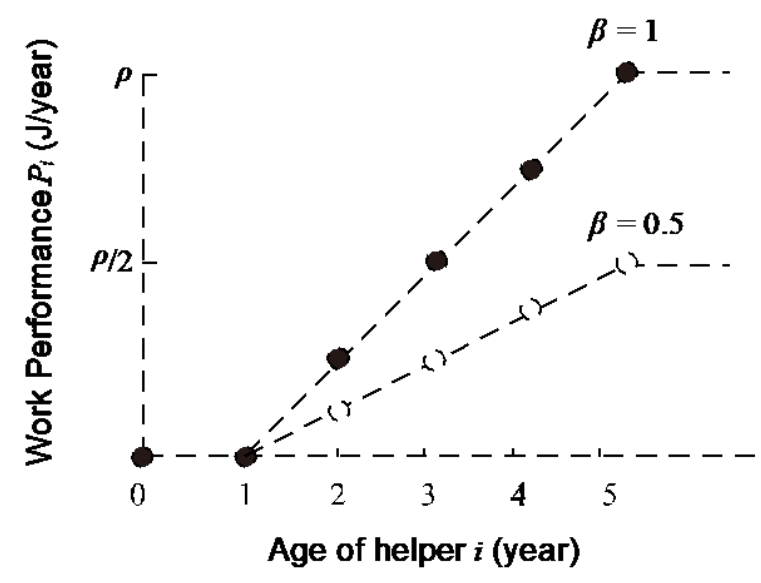

798

799 Fig. S3. Relationship between age and work performance of helpers. Work performance $P_{i}$ 800 (J/year) of a helper increases with age $i$ (year), where 0 -year-old and 1-year-old helpers do not 801 contribute to social labor. Offspring older than 5 years achieve their maximum possible performance $\beta \cdot \rho$, where $\beta$ is the relative work efficiency of helpers to the work performance of a parent $\rho$. If $\beta$ is 1 , mature helpers (offspring older than 5 years) have the same work performance 805 as a parent (closed circles). The 2-4 year old offspring have intermediate performance levels.

806 
bioRxiv preprint doi: https://doi.org/10.1101/2021.04.28.441822; this version posted April 29, 2021. The copyright holder for this preprint (which was not certified by peer review) is the author/funder, who has granted bioRxiv a license to display the preprint in perpetuity. It is made available under aCC-BY 4.0 International license.

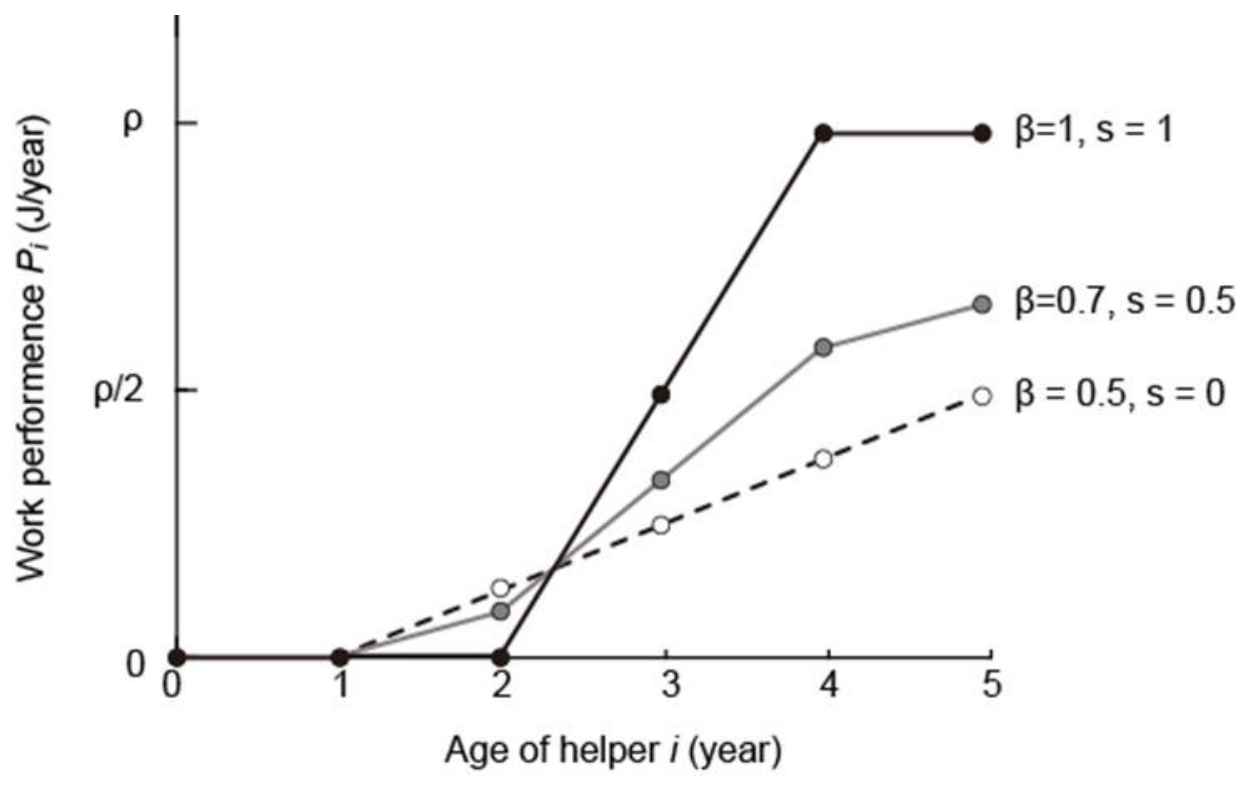

808

809 Fig. S4. Relationship between age and work performance of helpers. The work performance

$810 P_{i}$ of a helper at age $i$ (year) is given by Equation (S2).

811

812

813 

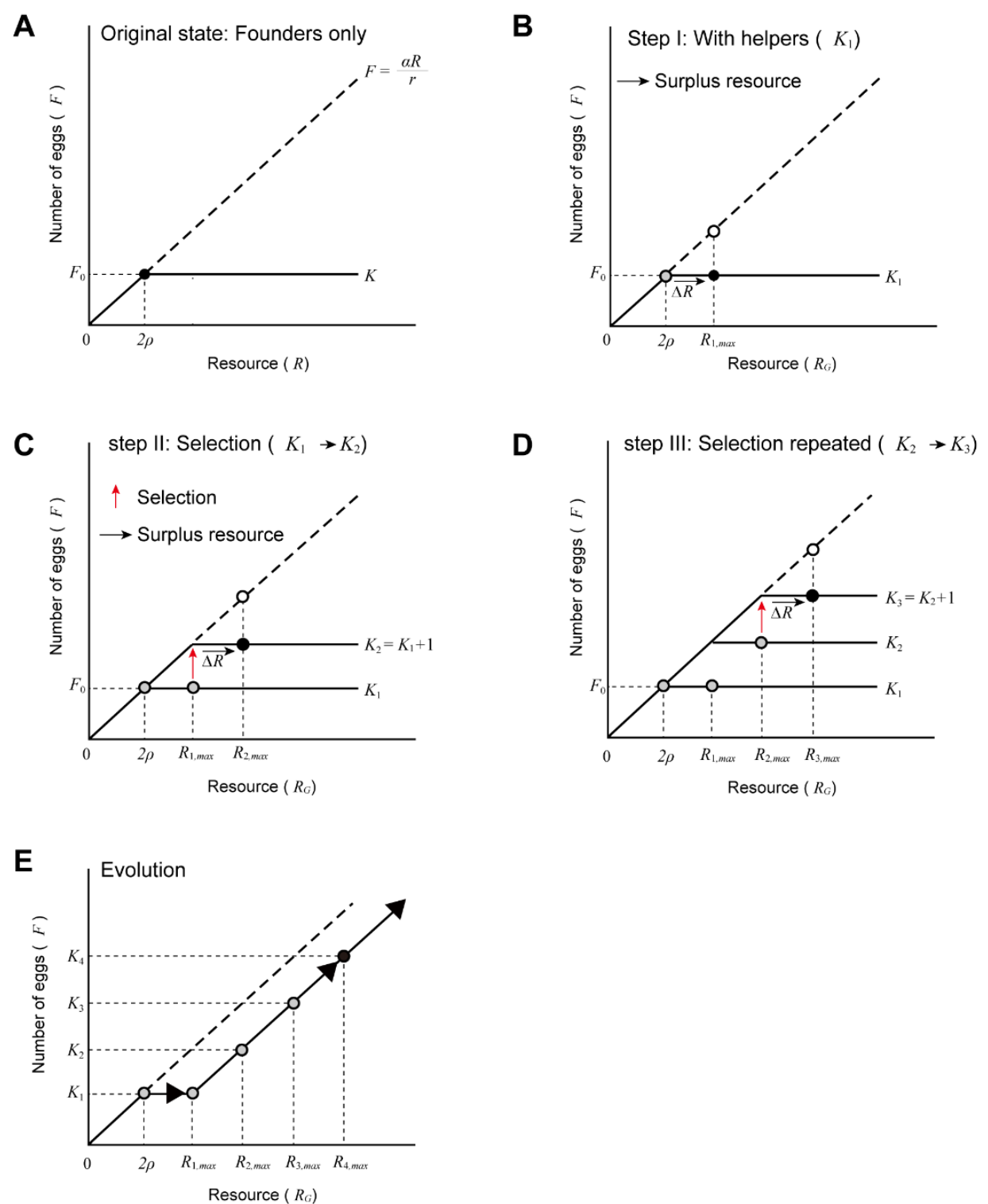

Fig. S5. Selection scheme. $(A)$ Original state. Without helpers, the founders reproduce by using their own resources $2 \rho$. A monogamous pair of a male and a female produce $F_{0}$ eggs using their own resources $2 \rho$. (B) Step I (generation $G_{1}$ ). Presence of helpers contribute to social labor, which increases the resources available $\Delta R$ for egg production. Nevertheless, the parents can produce only $F_{0}$ eggs because of limitations on maximum reproductive capacity $K_{1}$. (C) Step II (generation $G_{2}$ ). Selection favors higher reproductive capacity of the parents so as to fully utilize the available resources $\left(K_{1} \rightarrow K_{2}\right)$. Acquisition of greater reproductive potential is derived from higher epigenetic modification (canalization) of the genes for sexual development ${ }^{30,31}$. This leads to higher genomic imprinting and thus to the prolonged helper period of the offspring. Therefore, selection for higher $K$ moves the coordinate from $\left(R_{1, \max }, K_{1}\right)$ to $\left(R_{2, \max }, K_{2}\right)$. (D) Step III (generation $\left.G_{3}\right)$. In the same way as step II, selection favoring higher $K$ to utilize the surplus resources moves the coordinate from $\left(R_{2, \max }, K_{2}\right)$ to $\left(R_{3, \max }, K_{3}\right)$. (E) The evolutionary process. Trace of the evolution of 827 reproductive capacity starting from $K_{1}\left(=F_{0}\right)$. 


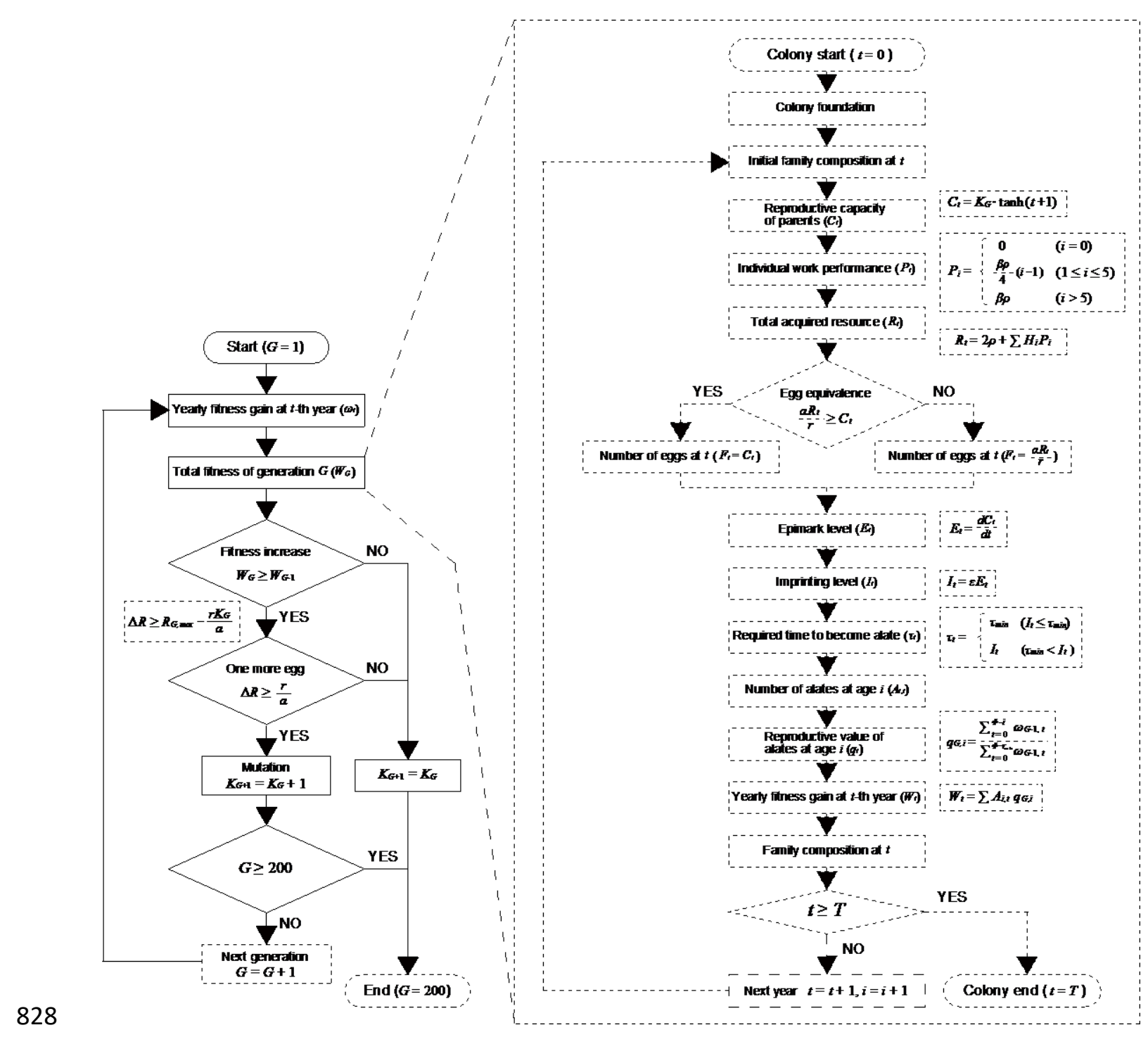

829

830 Fig. S6. Simulation flow. See Model for the detailed procedure. 
A

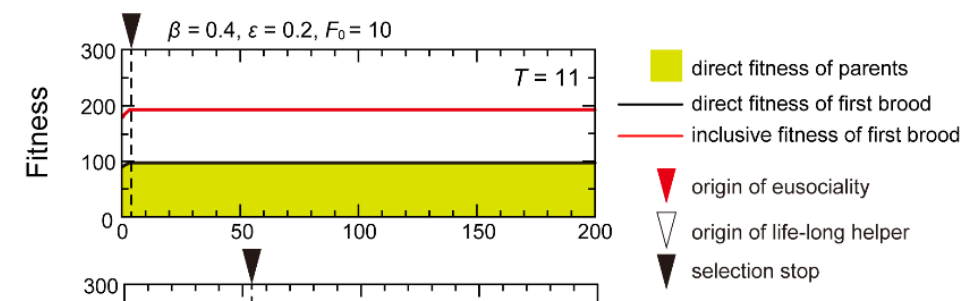

B

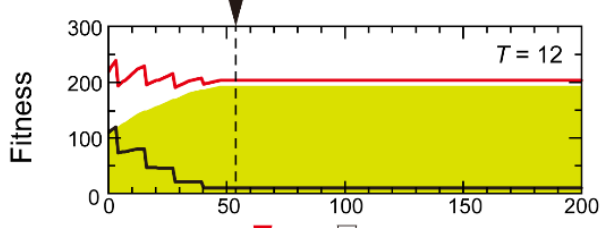

C

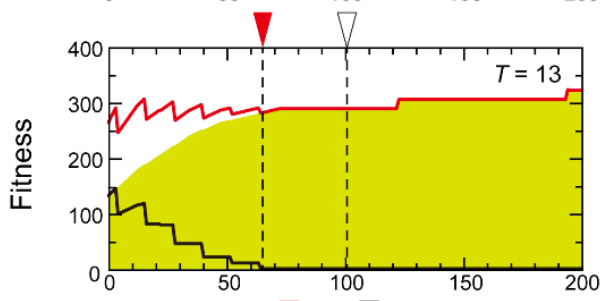

D

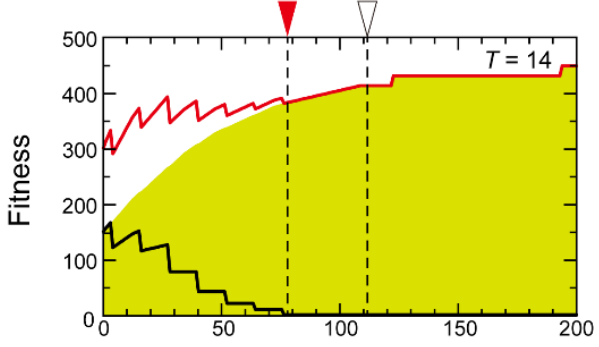

E

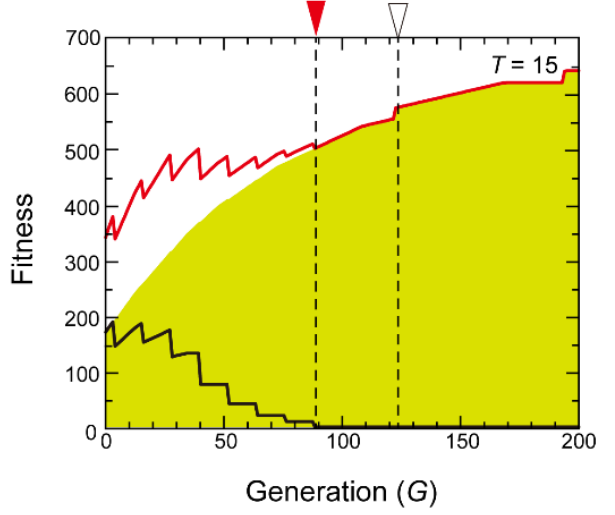

Fig. S7. Colony longevity and evolvability of eusociality. Fitness dynamics of the parents and the first brood offspring under different values of colony longevity $T$. $\left(\beta=0.4, \varepsilon=0.2, F_{0}=10\right)$. $(A$, $B$ ) Colony lifespan is too short for the inception of eusociality. Selection stops, that is, the direct fitness of the parents decreases, at generation $G=5$ when $T=11(A)$ and at $G=53$ when $T=12$ $(B)$ without reaching the threshold for eusociality. $(C-E)$ Colony lifespan is sufficient for the evolution of eusociality. Eusociality originates at $G=65$ when $T=13(C)$, at $G=77$ when $T=14$ (D) and at $G=89$ when $T=15(E)$. Green area indicates the direct fitness of parents (the number of alates produced by a colony). Black and red lines indicate the direct and inclusive fitness of the first brood, respectively. Red arrowheads indicate the origin of eusociality (the appearance of a helper with no direct fitness). Open arrowheads indicate the appearance of lifelong helper. Black arrowheads indicate the point when selection stops, i.e., the direct fitness of the parents is lower than that of the previous generation in numerical calculation. 
845 Table S1. The parameters of the genomic imprinting model

\begin{tabular}{|c|c|}
\hline Symbol & Definition \\
\hline$i$ & Age of offspring (years) \\
\hline$\Phi$ & Longevity of individuals (years) \\
\hline$\tau$ & Time from birth to dispersal (years) \\
\hline$t$ & Colony age (year), i.e., time after colony foundation \\
\hline$T$ & Longevity of a colony, i.e., $\Phi-T$ (years) \\
\hline$\omega_{t}$ & Fitness gain of the colony at $t$ \\
\hline$W$ & Total fitness of a colony \\
\hline$\rho$ & Work performance of an adult (a founding male or a founding female) \\
\hline$R_{t}$ & The available resources for egg production of a $t$-year-old colony \\
\hline$\alpha$ & Metabolic efficiency of the parents to convert the resources into eggs \\
\hline$r$ & Cost of producing one egg \\
\hline$F_{t}$ & The number of eggs produced in year $t$ \\
\hline$P_{i}$ & $\begin{array}{l}\text { Work performance ( } \mathrm{J} / \text { year), i.e., the total resources }(\mathrm{J}) \text { acquired by a single } \\
\text { helper at age } i \text { in one year }\end{array}$ \\
\hline$\beta$ & Relative work performance of a helper to that of a parent $\rho$ \\
\hline$H_{i}$ & Number of $i$-year-old helpers \\
\hline$C_{t}$ & $\begin{array}{l}\text { Reproductive capacity (eggs/year) of the parents of a } t \text {-year-old colony, that is, } \\
\text { the maximum number of eggs produced in year } t\end{array}$ \\
\hline$K_{G}$ & $\begin{array}{l}\text { The maximum reproductive capacity, i.e., reproductive capacity of fully-matured } \\
\text { parents of generation } G\end{array}$ \\
\hline$E_{t}$ & $\begin{array}{l}\text { Epimark level of the parents of a } t \text {-year-old colony, that is, the time derivative of } \\
\left.C_{t} \text { (Fig. } 3 B\right)\end{array}$ \\
\hline$\varepsilon$ & Relative strength of epigenetic inheritance \\
\hline$I_{t}$ & Imprinting level of the offspring produced in year $t$ \\
\hline$A_{i, t}$ & The number of $i$-year-old alates produced in year $t$ \\
\hline$q_{G, i}$ & The reproductive value of the $i$-year-old alate \\
\hline
\end{tabular}


bioRxiv preprint doi: https://doi.org/10.1101/2021.04.28.441822; this version posted April 29, 2021. The copyright holder for this preprint (which was not certified by peer review) is the author/funder, who has granted bioRxiv a license to display the preprint in perpetuity. It is made available under aCC-BY 4.0 International license.

\section{7}


bioRxiv preprint doi: https://doi.org/10.1101/2021.04.28.441822; this version posted April 29, 2021. The copyright holder for this preprint (which

was not certified by peer review) is the author/funder, who has granted bioRxiv a license to display the preprint in perpetuity. It is made available under aCC-BY 4.0 International license.

848 Table S2. Parameter combinations in figures

\begin{tabular}{llll}
\hline Figure & Simulation results & $\begin{array}{l}\text { Varied } \\
\text { Parameters }\end{array}$ & $\begin{array}{l}\text { Fixed } \\
\text { Parameters }\end{array}$ \\
\hline Fig. $4 A$ & Evolvability of eusociality & $\beta, F_{0}, T, \varepsilon$ & \\
Fig. $4 B-D$ & Fitness dynamics & $\beta$ & $F_{0}, \varepsilon, T$ \\
Fig. $4 E$ & $\begin{array}{l}\text { Generations required for the } \\
\text { origin of eusociality }\end{array}$ & $\varepsilon$ & $\beta, F_{0}, T$ \\
Fig. $\mathrm{S} 7$ & Fitness dynamics & $T$ & $\beta, F_{0}, \varepsilon$ \\
\hline
\end{tabular}

849

850 


\section{SI References}

Anway MD, Cupp AS, Uzumcu N, Skinner MK. 2005. Toxicology: Epigenetic transgenerational actions of endocrine disruptors and male fertility. Science 308:1466-1469. doi:10.1126/science. 1108190

Bonduriansky R, Day T. 2008. Nongenetic inheritance and its evolutionary implications. Annu Rev Ecol Evol Syst 40:103-125.

Cavalli G, Paro R. 1998. The Drosophila Fab-7 chromosomal element conveys epigenetic inheritance during mitosis and meiosis. Cell 93:505-518. doi:10.1016/S0092$8674(00) 81181-2$

Chong S, Whitelaw E. 2004. Epigenetic germline inheritance. Curr Opin Genet Dev 14:692-696. doi:10.1016/j.gde.2004.09.001

Daxinger L, Whitelaw E. 2012. Understanding transgenerational epigenetic inheritance via the gametes in mammals. Nat Rev Genet 13:153-162. doi:10.1038/nrg3188

Dedeine F, Dupont S, Guyot S, Matsuura K, Wang C, Habibpour B, Bagnères A-GA-G, Mantovani B, Luchetti A. 2016. Historical biogeography of Reticulitermes termites (Isoptera: Rhinotermitidae) inferred from analyses of mitochondrial and nuclear loci. Mol Phylogenet Evol 94, Part B:778-790. doi:10.1016/j.ympev.2015.10.020

Deegan DF, Engel N. 2019. Sexual dimorphism in the age of genomics: how, when, where. Frontiers in Cell and Developmental Biology 7:1-7. doi:10.3389/fcell.2019.00186

Ferguson-Smith AC. 2011. Genomic imprinting: the emergence of an epigenetic paradigm. Nat Rev Genet 12:565-575. doi:10.1038/nrg3032

Fougeyrollas R, Dolejšová K, Sillam-Dussès D, Roy V, Poteaux C, Hanus R, Roisin Y. 2015. Asexual queen succession in the higher termite Embiratermes neotenicus. Proceedings of the Royal Society B 282:20150260. doi:10.1098/rspb.2015.0260

Fougeyrollas R, Křivánek J, Roy V, Dolejšová K, Frechault S, Roisin Y, Hanus R, Sillam - Dussès D, Sillam-Dussès D. 2017. Asexual queen succession mediates an accelerated colony life cycle in the termite Silvestritermes minutus. Mol Ecol 26:3295-3308. doi: $10.1111 / \mathrm{mec} .14095$

Fournier D, Hellemans S, Hanus R, Roisin Y. 2016. Facultative asexual reproduction and genetic diversity of populations in the humivorous termite Cavitermes tuberosus. Proceedings of the Royal Society B 283:20160196.

Galbraith DA, Kocher SD, Glenn T, Albert I, Hunt GJ, Strassmann JE, Queller DC, Grozinger CM. 2016. Testing the kinship theory of intragenomic conflict in honey bees (Apis mellifera). Proc Natl Acad Sci U S A 113:1020-1025.

Gegner J, Baudach A, Mukherjee K, Halitschke R, Vogel H, Vilcinskas A. 2019. Epigenetic mechanisms are involved in sex-specific trans-generational immune priming in the lepidopteran model host manduca sexta. Front Physiol 10:1-13. doi:10.3389/fphys.2019.00137

Glastad KM, Gokhale K, Liebig J, Goodisman MAD. 2016. The caste- and sex-specific DNA methylome of the termite Zootermopsis nevadensis. Sci Rep 6:37110. doi:10.1038/srep37110

Goll MG, Bestor TH. 2005. Eukaryotic cytosine methyltransferases. Annu Rev Biochem 74:481514.

Greer EL, Shi Y. 2012. Histone methylation: A dynamic mark in health, disease and inheritance. Nat Rev Genet 13:343-357. doi:10.1038/nrg3173

Gregg C, Zhang J, Butler JE, Haig D, Dulac C. 2010. Sex-specific parent-of-origin allelic expression in the mouse brain. Science 329:682-685. doi:10.1126/science.1190831

Grewal SIS, Klar AJS. 1996. Chromosomal inheritance of epigenetic states in fission yeast during mitosis and meiosis. Cell 86:95-101. doi:10.1016/S0092-8674(00)80080-X

Hager R, Cheverud JM, Leamy LJ, Wolf JB. 2008. Sex dependent imprinting effects on complex traits in mice. BMC Evol Biol 8:303.

Haig D. 2014. Coadaptation and conflict, misconception and muddle, in the evolution of genomic imprinting. Heredity 113:96-103. doi:10.1038/hdy.2013.97 
Harrison MC, Jongepier E, Robertson HM, Arning N, Bitard-Feildel T, Chao H, Childers CP, Dinh H, Doddapaneni H, Dugan S, Gowin J, Greiner C, Han Y, Hu H, Hughes DST, Huylmans AK, Kemena C, Kremer LPM, Lee SL, Lopez-Ezquerra A, Mallet L, Monroy-Kuhn JM, Moser A, Murali SC, Muzny DM, Otani S, Piulachs MD, Poelchau M, Qu J, Schaub F, Wada-Katsumata A, Worley KC, Xie Q, Ylla G, Poulsen M, Gibbs RA, Schal C, Richards S, Belles X, Korb J, Bornberg-Bauer E. 2018. Hemimetabolous genomes reveal molecular basis of termite eusociality. Nature Ecology and Evolution 2:557-566. doi:10.1038/s41559-017-0459-1

Hauser M-T, Aufsatz W, Jonak C, Luschnig C. 2011. Transgenerational epigenetic inheritance in plants. Biochim Biophys Acta 1809:459-468. doi:10.1016/j.bbagrm.2011.03.007.Transgenerational

Hayashi Y, Lo N, Miyata H, Kitade O. 2007. Sex-linked genetic influence on caste determination in a termite. Science 318:985-987.

Hellemans S, Dolejšová K, Křivánek J, Fournier D, Hanus R, Roisin Y. 2019. Widespread occurrence of asexual reproduction in higher termites of the Termes group (Termitidae: Termitinae). BMC Evol Biol 19:1-14. doi:10.1186/s12862-019-1459-3

Hellemans S, Roisin Y. 2020. Asexual queen succession in termites. Elsevier Oceanogr Ser 1:13-20. doi:10.1002/9780470015902.a0029115

Holman L, Kokko H. 2014. The evolution of genomic imprinting: Costs, benefits and long-term consequences. Biol Rev Camb Philos Soc 89:568-587. doi:10.1111/brv.12069

Jablonka E, Raz G. 2009. Transgenerational epigenetic inheritance: prevalence, mechanisms, and implications for the study of heredity and evolution. Q Rev Biol 84:131-176. doi: $10.1086 / 598822$

Kearns M, Preis J, McDonald M, Morris C, Whitelaw E. 2000. Complex patterns of inheritance of an imprinted murine transgene suggest incomplete germline erasure. Nucleic Acids Res 28:3301-3309. doi:10.1093/nar/28.17.3301

Kitade O, Hoshi M, Odaira S, Asano A, Shimizu M, Hayashi Y, Lo N. 2010. Evidence for genetically influenced caste determination in phylogenetically diverse species of the termite genus Reticulitermes. Biol Lett rsbl20100856.

Lawson HA, Cheverud JM, Wolf JB. 2013. Genomic imprinting and parent-of-origin effects on complex traits. Nat Rev Genet 14:609-617. doi:10.1038/nrg3543

Liberman N, Wang SY, Greer EL. 2019. Transgenerational epigenetic inheritance: from phenomena to molecular mechanisms. Curr Opin Neurobiol 59:189-206. doi:10.1016/j.conb.2019.09.012

Luchetti A, Velonà A, Mueller M, Mantovani B. 2013. Breeding systems and reproductive strategies in Italian Reticulitermes colonies (Isoptera: Rhinotermitidae). Insectes Soc 60:203-211.

Martin C, Zhang Y. 2007. Mechanisms of epigenetic inheritance. Curr Opin Cell Biol 19:266-272. doi:10.1016/j.ceb.2007.04.002

Matsuura K. 2020. Genomic imprinting and evolution of insect societies. Popul Ecol 62:38-52. doi:10.1002/1438-390x.12026

Matsuura K. 2017. Evolution of the asexual queen succession system and its underlying mechanisms in termites. J Exp Biol 220:63-72. doi:10.1242/jeb.142547

Matsuura K, Mizumoto N, Kobayashi K, Nozaki T, Fujita T, Yashiro T, Fuchikawa T, Mitaka Y, Vargo EL. 2018. A genomic imprinting model of termite caste determination: Not genetic but epigenetic inheritance influences offspring caste fate. Am Nat 191:677-690. doi:10.1086/697238

Matsuura K, Vargo EL, Kawatsu K, Labadie PE, Nakano H, Yashiro T, Tsuji K. 2009. Queen succession through asexual reproduction in termites. Science 323:1687. doi:10.1126/science.1169702

Miryeganeh M, Saze H. 2020. Epigenetic inheritance and plant evolution. Popul Ecol 62:17-27. doi:10.1002/1438-390X.12018

Miska EA, Ferguson-smith AC. 2016. Transgenerational inheritance: Models and mechanisms of non - DNA sequence - based inheritance 354:778-782. 
959 Mitaka Y, Tasaki E, Nozaki T, Fuchikawa T, Kobayashi K, Matsuura K. 2020. Transcriptomic

1000

1001

1002

1003

1004

1005

1006

1007

1008 analysis of epigenetic modification genes in the termite Reticulitermes speratus. Insect Sci 27. doi: $10.1111 / 1744-7917.12640$

Moazed D. 2011. Mechanisms for the inheritance of chromatin states. Cell 146:510-518. doi:10.1016/j.cell.2011.07.013

Morgan CP, Bale TL. 2011. Early prenatal stress epigenetically programs dysmasculinization in second-generation offspring via the paternal lineage. Journal of Neuroscience 31:1174811755. doi:10.1523/JNEUROSCI.1887-11.2011

Mukherjee K, Vilcinskas A. 2019. Transgenerational epigenetic inheritance in insects In: Tollefsbol TO, editor. Transgenerational Epigenetics. Academic Press. pp. 315-329.

Nozaki T, Yashiro T, Matsuura K. 2018. Preadaptation for asexual queen succession: queen tychoparthenogenesis produces neotenic queens in the termite Reticulitermes okinawanus. Insectes Soc. doi:10.1007/s00040-018-0603-1

Patten MM, Ross L, Curley JP, Queller DC, Bonduriansky R, Wolf JB. 2014. The evolution of genomic imprinting: Theories, predictions and empirical tests. Heredity 113:119-128. doi:10.1038/hdy.2014.29

Perez MF, Lehner B. 2019. Intergenerational and transgenerational epigenetic inheritance in animals. Nat Cell Biol 21:143-151. doi:10.1038/s41556-018-0242-9

Reik W, Walter J. 2001. Genomic imprinting: parental influence on the genome. Nat Rev Genet 2:21-32. doi:10.1038/35047554

Remy JJ. 2010. Stable inheritance of an acquired behavior in Caenorhabditis elegans. Curr Biol 20:877-878. doi:10.1016/j.cub.2010.08.013

Rice WR, Friberg U, Gavrilets S. 2016. Sexually antagonistic epigenetic marks that canalize sexually dimorphic development. Mol Ecol 25:1812-1822.

Rice WR, Friberg U, Gavrilets S. 2013. Homosexuality via canalized sexual development: a testing protocol for a new epigenetic model. Bioessays 35:764-770.

Rice WR, Friberg U, Gavrilets S. 2012. Homosexuality as a consequence of epigenetically canalized sexual development. Q Rev Biol 87:343-368.

Serobyan V, Sommer RJ. 2017. Developmental systems of plasticity and trans-generational epigenetic inheritance in nematodes. Curr Opin Genet Dev 45:51-57. doi:10.1016/j.gde.2017.03.001

Suzuki S, Ono R, Narita T, Pask AJ, Shaw G, Wang C, Kohda T, Alsop AE, Marshall Graves JA, Kohara Y, Ishino F, Renfree MB, Kaneko-Ishino T. 2007. Retrotransposon silencing by DNA methylation can drive mammalian genomic imprinting. PLoS Genet 3. doi:10.1371/journal.pgen.0030055

Szyf M. 2014. Lamarck revisited: epigenetic inheritance of ancestral odor fear conditioning. Nat Neurosci 17:2.

Thorne BL. 1997. Evolution of eusociality in termites. Annu Rev Ecol Syst 28:27-54.

Vargo EL, Labadie PE, Matsuura K. 2012. Asexual queen succession in the subterranean termite Reticulitermes virginicus. Proceedings of the Royal Society B 279:813-819. doi:10.1098/rspb.2011.1030

Vigé A, Gallou-kabani C, Junien C. 2008. Sexual dimorphism in non-mendelian inheritance. Pediatr Res 63:340-347.

Xu W, Dai M, Li F, Liu A. 2014. Genomic imprinting, methylation and parent-of-origin effects in reciprocal hybrid endosperm of castor bean. Nucleic Acids Res 42:6987-6998. doi:10.1093/nar/gku375

Yan H, Bonasio R, Simola DF, Liebig J, Berger SL, Reinberg D. 2015. DNA methylation in social insects: how epigenetics can control behavior and longevity. Annu Rev Entomol 60:435452. 
bioRxiv preprint doi: https://doi.org/10.1101/2021.04.28.441822 this version posted April 29, 2021. The copyright holder for this preprint (which A was not certified by peer review) is the author/funder, who granted bioRxiv a license to displaveth nt in perpetuity. It is made
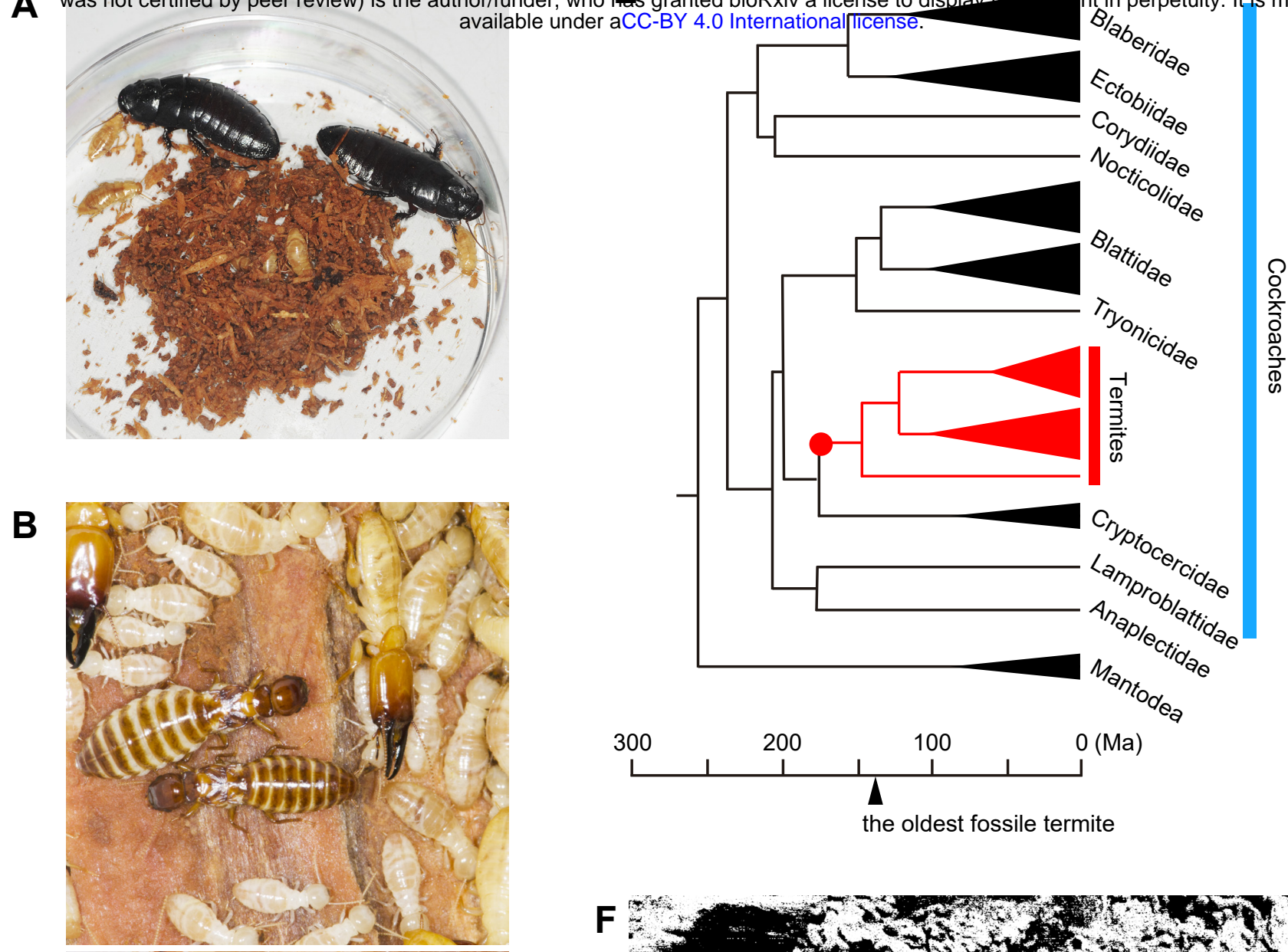

C

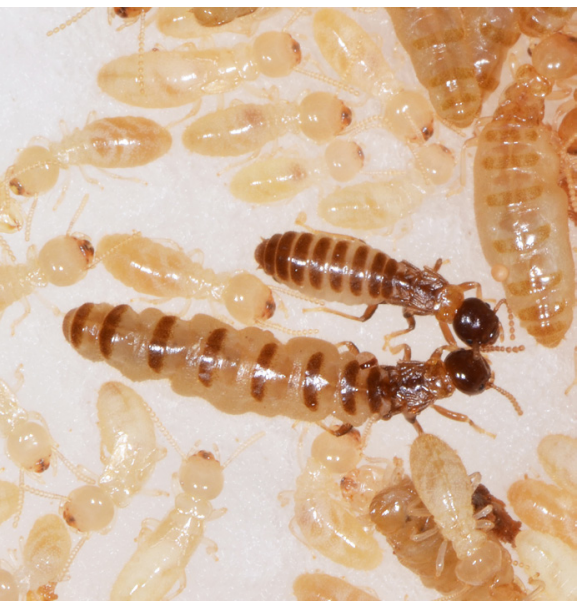

D

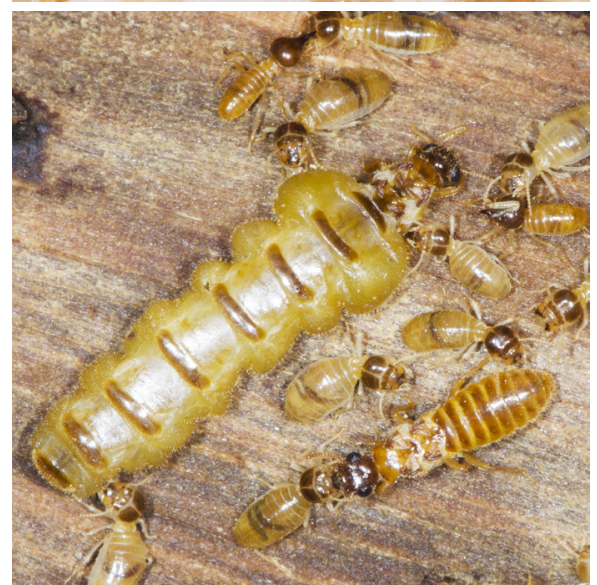

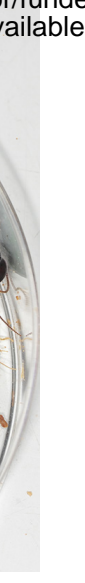


A

bioRxiv preprint doi: https://doi.org/10.1101/2021.04.28.441822; this version posted April 29, 2021. The cbtpyegs S was not certified by peer review) is the author/funder, who has granted bioRxiv a license to display the preprint in perpetuity. It is made available under aCC-BY 4.0 International license.

Focal colony

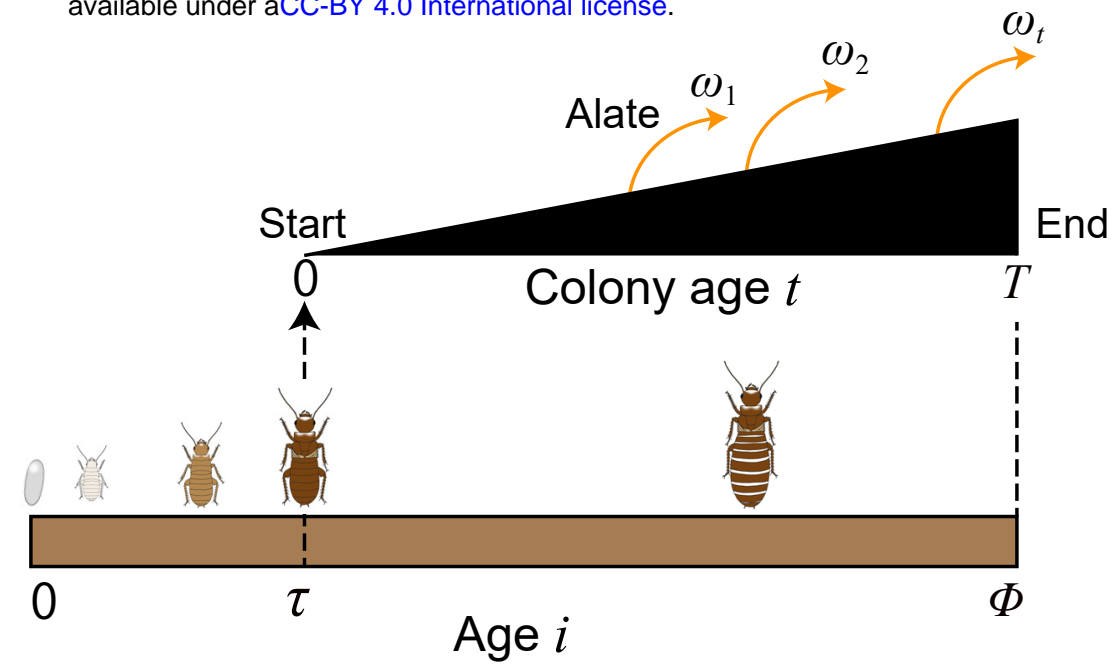

B

Founder's life

Age $i$

$1 \mathrm{st}$

helper contribution

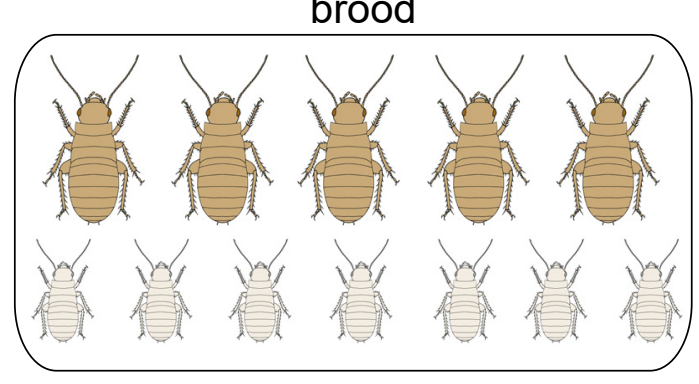

2nd

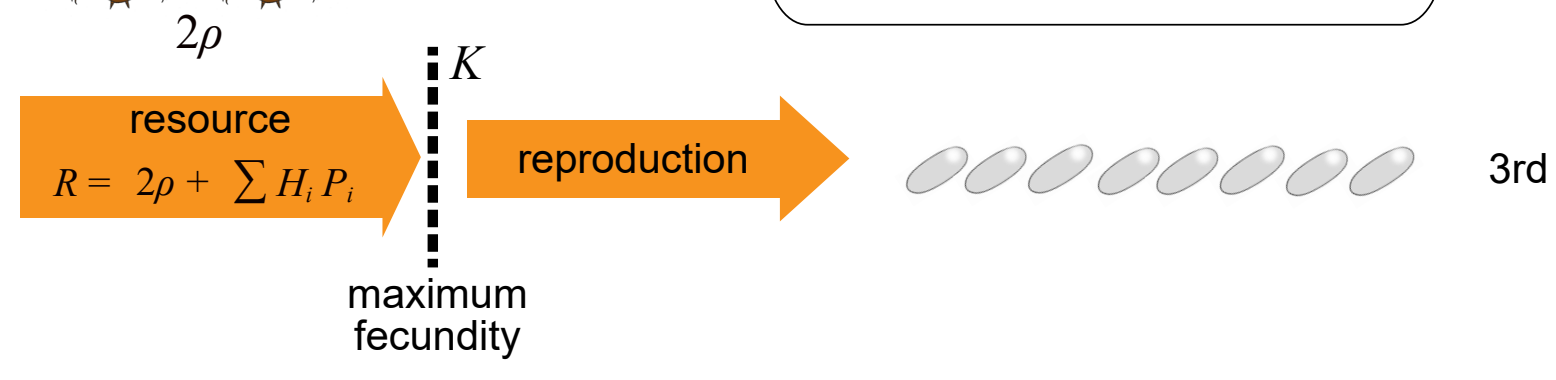

C Original state

Generation $G_{1}$

Generation $G_{2}$

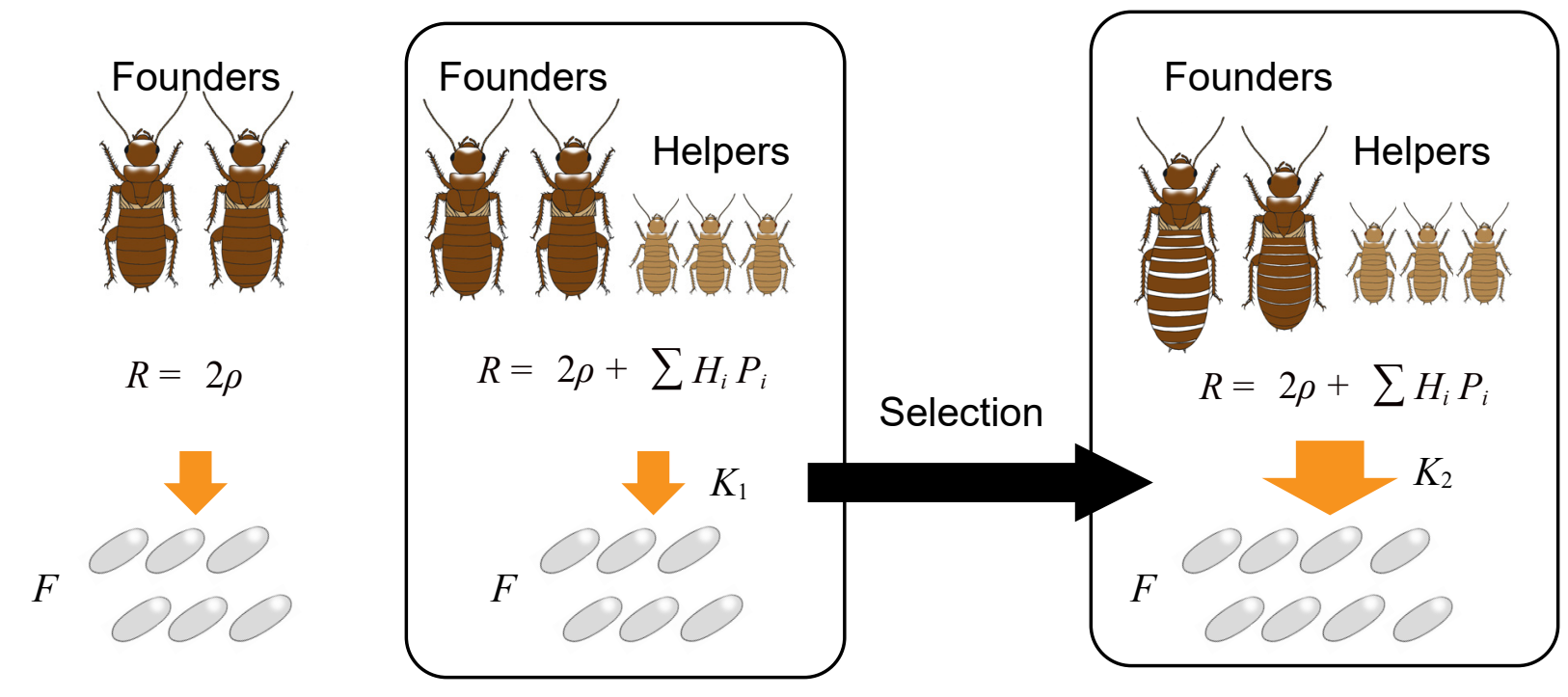

Fig. 2 
bioRxiv preprint doi: https://doi.org/10.1101/2021.04.28.441822; this version posted April 29, 2021. The copyright holder for this preprint (which A was not certified by peer review) is the author/funder, who has granted bioRxiv a license to display the preprint in perpetuity. It is made
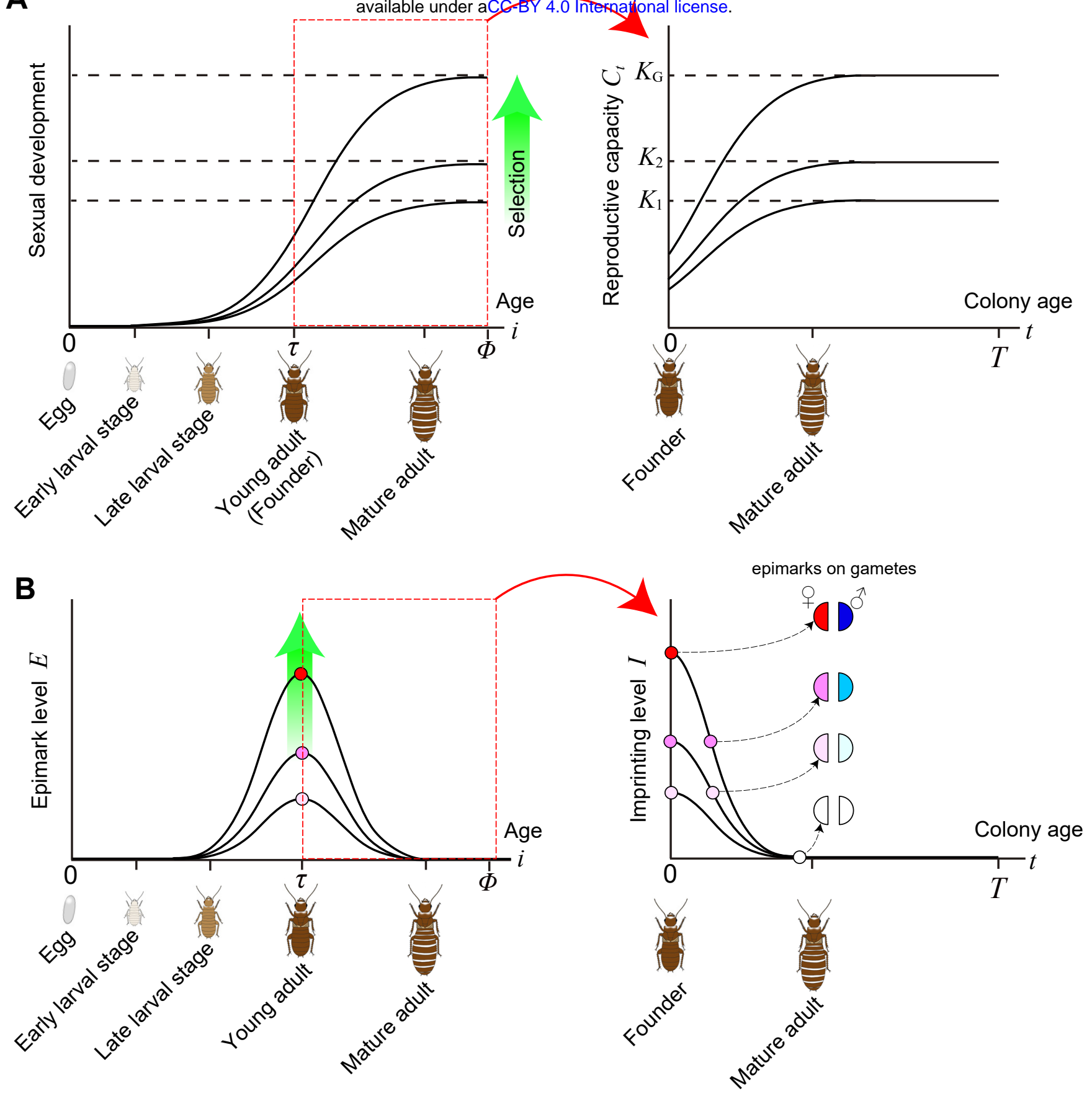

C
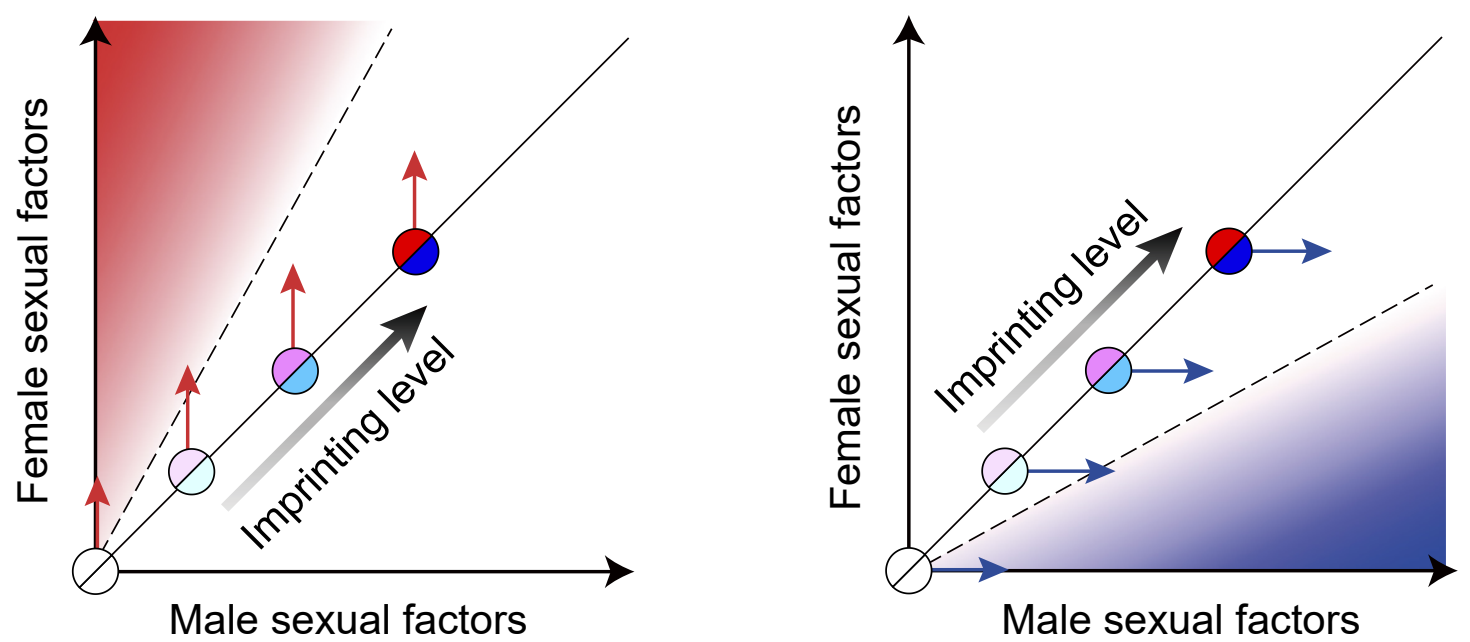

Fig. 3 


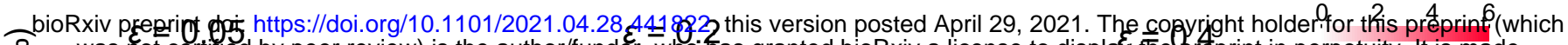
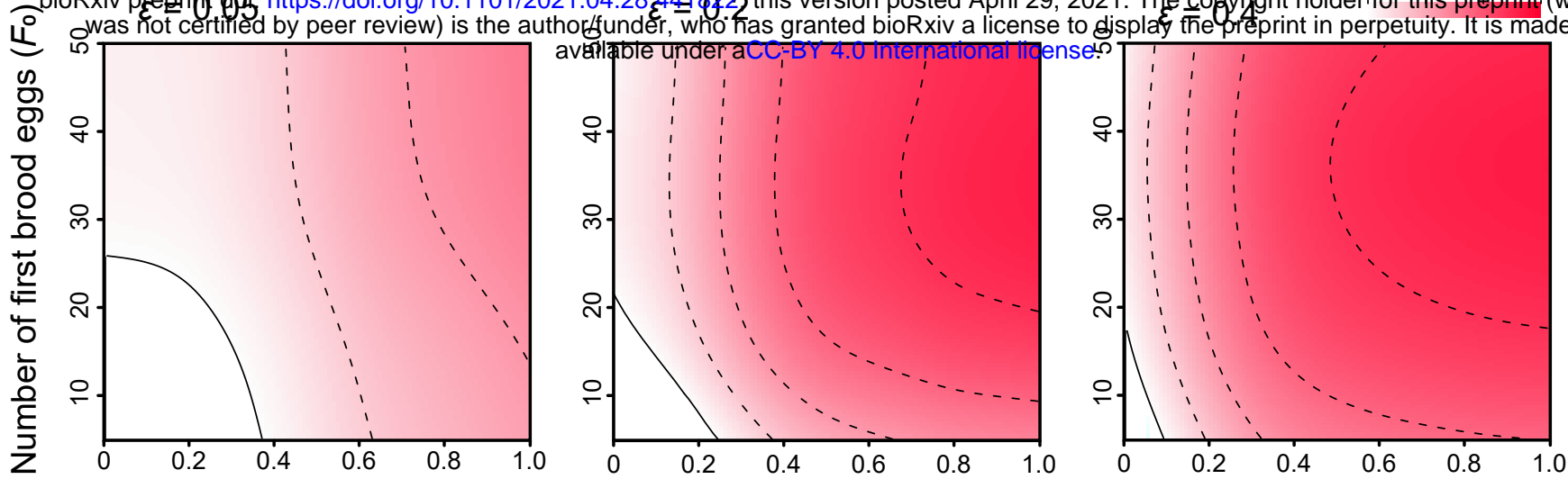

Relative work performance $(\beta)$

\section{B}

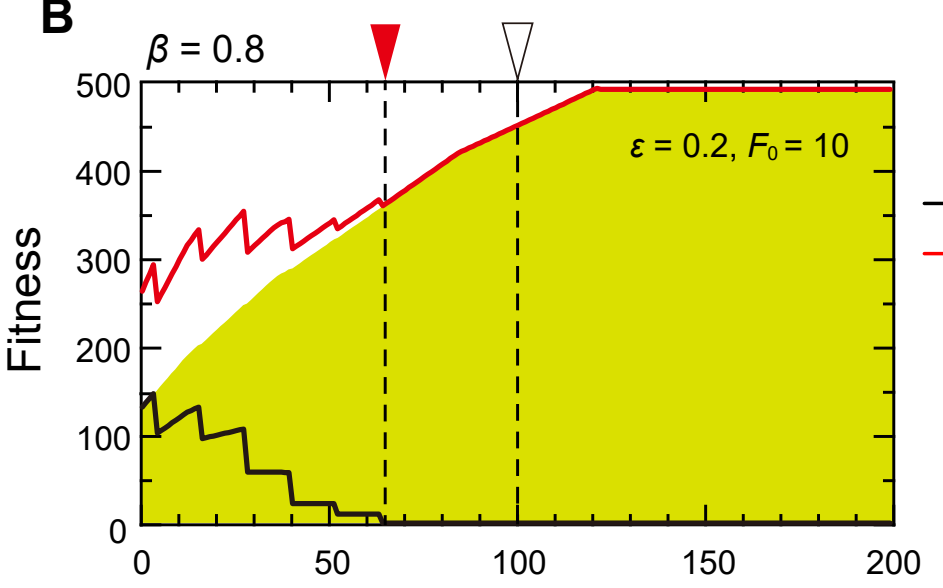

C
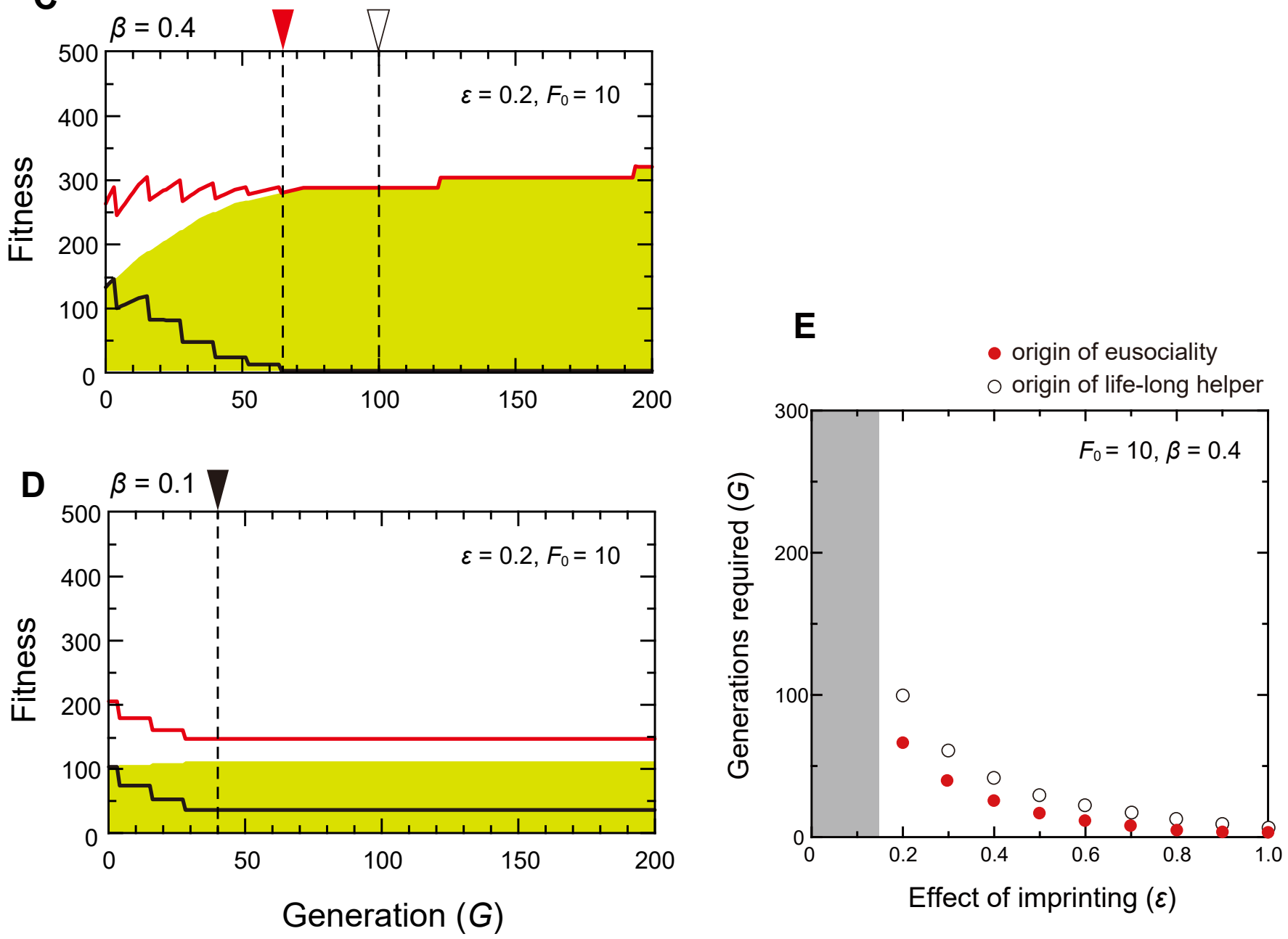

direct fitness of parents

direct fitness of first brood

inclusive fitness of first brood

origin of eusociality

$\nabla$ origin of life-long helper

selection stop

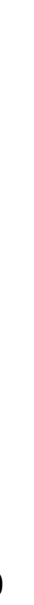

